\title{
Regular Spectral Transmittance
}

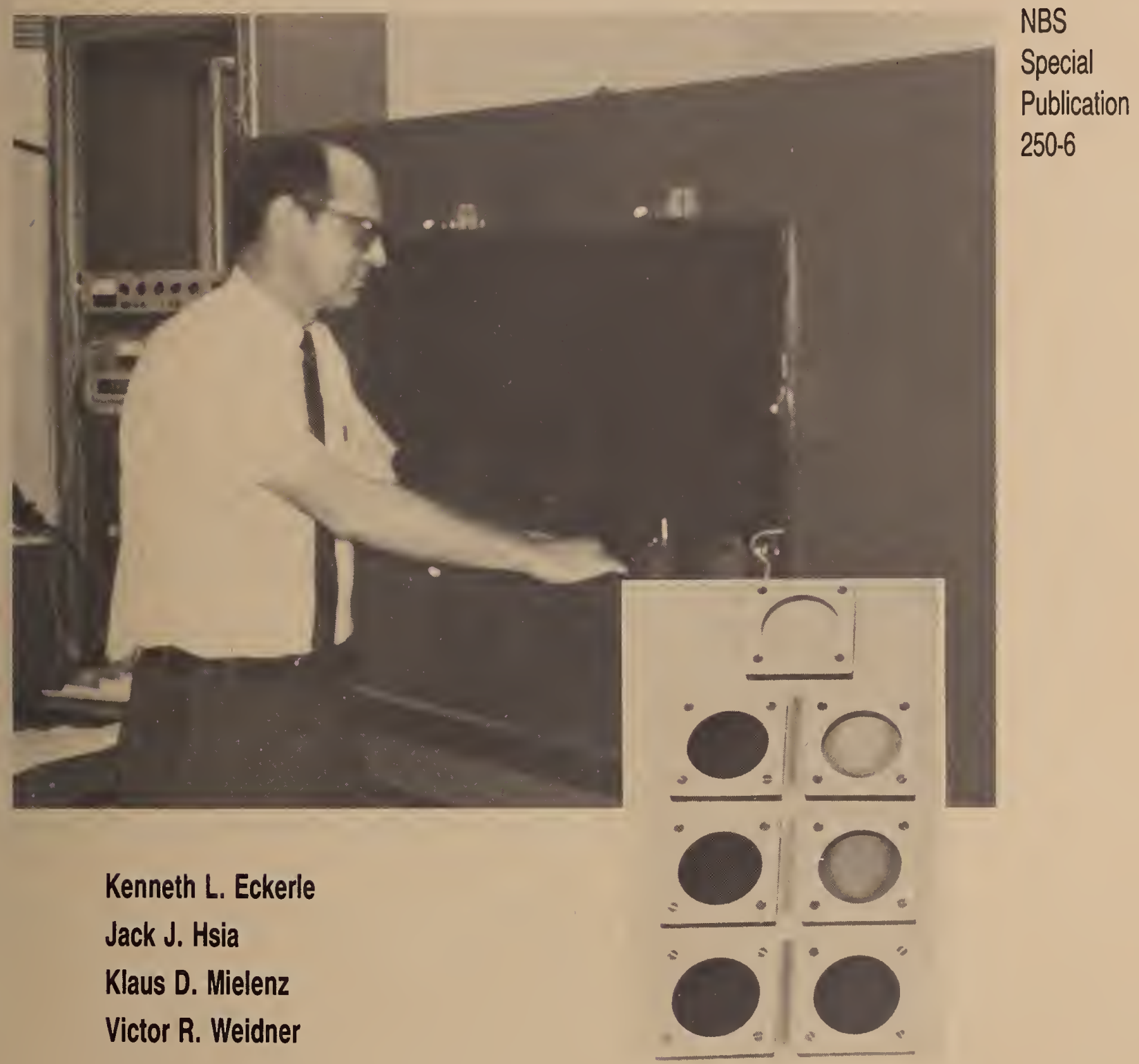

U.S. Department of Commerce National Bureau of Standards 


\section{Center for Radiation Research}

The Center for Radiation Research is a major component of the Nat fonal Measurement Laboratory in the Nat ional Bureau of Standards. The Center provides the Nation with standards and measurement services for ionizing radiation and for ultraviolet, visible, and infrared radiation; coordinates and furnishes essential support to the National Measurement Support System.for ionizing radiation; conducts research in radiation related fields to develop improved radiation measurement methodology; and generates, compiles, and critically evaluates data to meet major national needs. The Center consists of five Divisions and one Group.

\section{Atomic and Plasma Radiation Division}

$\begin{array}{lll}\text { Carries out basic theoretical and experimental research into the } & \text { Atomic Spectroscopy } \\ \text { spectroscopic and radiative properties of atoms and highly ionized } & \text { Atomic Radiation Data } \\ \text { species; develops well-defined at omic radiation sources as radiometric } & \text { - Plasma Radiation }\end{array}$
or wavelength standards; develops new measurement techniques and methods for spectral analysis and plasma properties; and collects, compiles, and critically evaluates spectroscopic data. The Division consists of the following Groups:

\section{Radiation Physics Division}

Provides the central national basis for the measurement of far ultraviolet, soft $x-r a y$, and electron radiation; develops and disseminates radiation standards, measurement services, and data for for these radiations; conducts theoretical and experimental research with electron, laser, ultraviolet, and soft $x-r$ ay $r$ adiation for measurement applications; determines fundamental mechanisms of electron and photon interactions with matter; and develops advanced electron- and photon-based measurement techiques. The Division consists of the following Groups:
- Far UV Physícs

- Electron Physics

- Photon Physics

\section{Radiometric Physics Division}

Provides national measurement standards and support services for ultraviolet, visible, and infrared radiation; provides standards dissemination and measurement quality assurance services; conducts research in optical radiation, pyrometry, photometry, and quantum radiometry; and develops spectroradiometric and spectrophotometric standards and calibration procedures. The Division consists of the following Groups:

\section{Radiation Source and Instrumentation Division}

\section{Develops, operates, and improves major NBS radiation facilities} including the electron Linac and race track microtron; develops, designs, and builds electronic and mechanical instrumentation for radiation programs and facilities; provides national leadership in the standardization of nuclear instrumentation; and develops new competence in radiation sources and instrument ation. The Division consists of the following Groups:

\section{lonizing Radiation Division}

Provides primary national standards, measurement services, and basic data for applications of ionizing radiation; develops new methods of chemical and physical dosimetry; conducts theoretical and experimental research on the fundamental physical and chemical interactions of ionizing radiation with matter; provides essential standards and measurement support services to the National Measurement Support System for Ionizing Radiation; and develops and operates radiation sources needed to provide primary radiation standards, fields, and well-characterized beams of radiation for research on radiation interactions and for development of measurement methods. The Division consists of the following office and Groups:
- Spectral Radiometry

- Spectrophotometry

- Radiometric Measurement Services

\section{Nuclear Physics Group}

\section{Engages in forefront research in nuclear and element ary particle physics;}

performs highly accurate measurements and theoretical analyses which probe the structure of nuclear matter; and improves the quant itative understanding of physical processes that underlie measurement science. 


\section{NBS MEASUREMENT SERVICES: \\ REGULAR SPECTRAL TRANSMITTANCE}

Kenneth L. Eckerle

Jack J. Hsia

Klaus D. Mielenz

Victor R. Weidner

Center for Radiation Research

National Measurement Laboratory

National Bureau of Standards

Gaithersburg, MD 20899

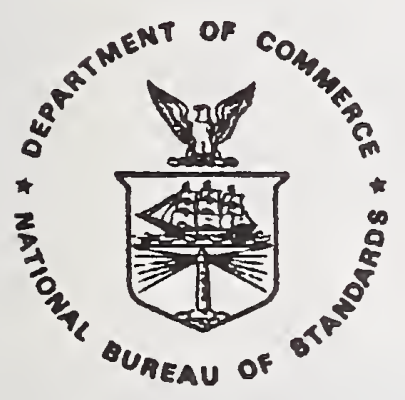

U.S. DEPARTMENT OF COMMERCE, Malcolm Baldrige, Secretary NATIONAL BUREAU OF STANDARDS, Ernest Ambler, Director Issued July 1987 


\section{Library of Congress Catalog Card Number: $87-619840$}

National Bureau of Standards Special Publication 250-6 Natl. Bur. Stand. (U.S.), Spec. Publ. 250-6, 59 pages (July 1987) CODEN: XNBSAV

Commercial products - materials and instruments - are identified in this document for the sole purpose of adequately describing experimental or test procedures. In no event does such identification imply recommendation or endorsement by the National Bureau of Standards of a particular product; nor does it imply that a named material or instrument is necessarily the best available for the purpose it serves.

\section{U.S. GOVERNMENT PRINTING OFFICE}

WASHINGTON: 1987

For sale by the Superintendent of Documents, U.S. Government Printing Office, Washington, DC 20402-9325 
The calibration and related measurement services of the National Bureau of Standards are intended to assist the makers and users of precision measuring instruments in achieving the highest possible levels of accuracy, quality, and productivity. NBS offers over 300 different calibration, special test, and measurement assurance services. These services allow customers to directly link their measurement systems to measurement systems and standards maintained by NBS. These services are offered to the public and private organizations alike. They are described in NBS Special Publication (SP) 250, NBS Calibration Services Users Guide.

The Users Guide is being supplemented by a number of special publications (designated as the "SP 250 Series") that provide a detailed description of the important features of specific NBS calibration services. These documents provide a description of the:

(1) specifications for the service; (2) design philosophy and theory;

(3) NBS measurement system; (4) NBS operational procedures; (5) assessment of measurement uncertainty including random and systematic errors and an error budget; and (6) internal quality control procedures used by NBS. These documents will present more detail than can be given in an NBS calibration report, or than is generally allowed in articles in scientific journals. In the past NBS has published such information in a variety of ways. This series will help make this type of information more readily available to the user.

This document (SP 250-6), NBS Measurement Services: Regular Spectral Transmittance, by K. L. Eckerle, J. J. Hsia, K. D. Mielenz, and V. R. Weidner, is the sixth to be published in this new series of special publications. It describes measurement services, instrumentation, standards, and measurement techniques for regular spectral

transmittance over the ultraviolet, visible, and near-infrared spectral ranges, from 200 to $2500 \mathrm{~nm}$ (see test numbers 38060S and 38010C-38050C in the SP 250 Users Guide). Inquiries concerning the technical content of this document or the specifications for these services should be directed to the authors or one of the technical contacts cited in SP 250 .

The Center for Radiation Research (CRR) is in the process of publishing 21 documents in this SP 250 series, covering all of the calibration services offered by CRR. A complete listing of these documents can be found inside the back cover.

NBS would welcome suggestions on how publications such as these might be made more useful. Suggestions are also welcome concerning the need for new calibration services, special tests, and measurement assurance programs.

George A. Uriano

Director

Measurement Services
Chris E. Kuyatt

Director

Center for Radiation Research 


\section{Abstract}

This documentation describes measurement services, instrumentation, standards, and measurement techniques for reqular spectral transmittance over the spectral range of 200 to $2500 \mathrm{~nm}$. It is divided into three parts. Part I describes the services and standards that are available and the quiding philosophy behind the efforts to provide a primary laboratory for spectral transmittance measurements. Part II describes the high accuracy reference spectrophotometer. Part III describes the high precision transfer spectrophotometer. The transfer instrument relies on master standards that are periodically calibrated using the reference spectrophotometer.

Key words: calibration; high accuracy; linearity; measurement service; stray light; transmittance; uncertainty; wave length. 
I. Measurement Services, Philosophy and Available Standards ..... 1

A. Measurement Philosophy ............... 1

B. Description of Services. ............ 1

C. St andard Reference Materials and Measurement Assurance Program 3

II. Reference Spectrophotometer for Regular Spectral Transmittance. . 3

A. Definition of "True" Regular Spectral Transmittance. . . . . 3

B. Instrumentation. .............. . . 9

1. Basic Instrument . . . . . . . . . . . . 9 9

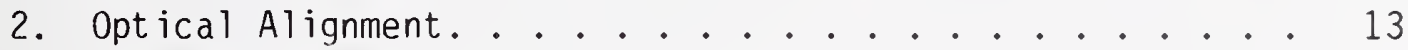

3. Automation .................. 13

a. Hardware ............... . 13

b. Software .............. . . 13

4. Measurement Capabilities and Required Sample Properties . 14

a. Identification . . . . . . . . . . . . 14

b. Stability................ 14

c. Cleaning.................. 14

d. Measured Area . . . . . . . . . . . 15

e. Uniformity .............. . . 15

f. Polarization ............... 15

g. Temperature. . . . . . . . . . . . 16

h. Solid Angle of Collection. . . . . . . . . 16

i. Angle of Incidence ............ . . 16

j. Filter Size ............... . . 17

k. Wave length .............. . . 17

1. Bandwidth .............. . . 17

m. Transmitt ance Range . . . . . . . . . . . 19

C. Instrument Calibration and Internal Quality Control. . . 19

1. Wave length Accuracy ............ 19

2. Linearity of the Photometric Scale ......... 23

3. Stability of Source and Detection System . . . . . . 25

4. Stray Radiant Power. . . . . . . . . . . . 25

D. Measurement Procedure. . . . . . . . . . . 25

1. Sample Preparation . . . . . . . . . . . 25

2. Sample Alignment ............. . . 26

3. Sample Uniformity ............. . . 26

4. Polarization .............. . . . 26

5. Data Acquisition and Reduction ......... . 26

a. Transmittance ............ . . 26

b. Linearity .............. . . . 28

E. Uncertainties .............. . . . 30

1. Instrumental Bias ............. . . 30

2. Random Errors ... . . . . . . . . . . 31

3. Sample-Induced Uncertainties .......... . 31

4. Total Uncertainty ............. . . 33

F. Report of Test ............... . . 33

G. Safety................... 33 
III. Transfer Spectrophotometer for Regular Transmittance . . . . 35

A. Descripton of the Instrument .......... 35

1. Wavelength Range .......... 35

2. Bandwidth Range. . . . . . . . . . . 35

3. Photometric Range. . . . . . . . . . . 35

4. Temperature Control. ............ 36

5. Data Acquisition and Automation ......... 36

B. Instrument Calibration ............ 36

1. Wavelength ............ . . 36

2. Linearity. ............. . . . 38

3. Stray Radiation. . . . . . . . . . . 39

4. Stability ................. 40

C. Operational Procedures .............. 40

1. Instrument Parameters. . . . . . . . . . . 40

2. Measurement Sequence for Transmittance or Absorbance . . 41

3. Data Reduction ............... 41

4. Uncertainties.............. 41

D. Reports of Test................ 42

E. Safety.................... 42

References ................... . . 44

Appendix A . . . . . . . . . . . . . A-1

Appendix B ............................ B-1 
TABLE OF CONTENTS (cont'd)

\section{LIST OF TABLES}

1. Calibration Services for Spectrophotometry .......... 2

2. Standard Reference Materials for Spectrophotometry . . . . . 4

3. Range, Source, Grating, Detector and Measurement Mode for Wave length Ranges. . . . . . . . . . . . . . . 18

4. Wavelengths of Atomic Emission Lines Used for Wavelength Calibrations in the UV and Visible Spectrum . . . . . . . . 20

a. Lines used with the $.25 \mathrm{~mm}$ apertures . . . . . . . . . . 20

b. Lines used with the $1 \mathrm{~mm}$ apertures ........... . 20

5. Wavelengths of Atomic Emission Lines and Molecular Absorption Bands Used for Wavelength Calibration in the Near IR Spectrum . . 21

6. Typical Over-all Uncertainties for NBS Reference Spectrophotometer . . . . . . . . . . . . . . 34

7. Emission Lines and Absorption Bands Used to Calibrate the Transfer Spectrophotometer Wave length Scale . . . . . . . . 37 Emission Lines . . . . . . . . . . . . . . . . . . . 37 Absorption Bands of Materials. . . . . . . . . . . . 37

8. Summary of Estimated Uncertainties in Percent of Spectral Transmittance Values for NBS Transfer Spectrophotometer [A Representative Analysis (Three Sigma) in the Visible Region for Tr ansmittances in the Range .1-1.0] . . . . . . . . . . . 
Fig. 1. Diagram Pertaining to the Definition of Reqular Transmittance .............. . . 6

Fig. 2. Schematic of Reference Spectrophotometer as Used in the Ultraviolet and Visible ............... 10

Fig. 3. Schematic of Reference Spectrophotometer as Used in the Near Infrared . . . . . . . . . . . . 12

Fig. 4. Example of Additive Wavelength Correction Curve . . . . 22

Fig. 5. Additive Correction, $\Delta T$, Versus Transmittance $T(\phi)$. The Shaded Area respresents \pm 1 St andard Deviation . . . . . . . 24

Fig. 6. Systematic and Random (Standard Deviation) as a Function of Transmittance on a Log-Log Plot ........... 32 
I. Measurement Services, Philosophy and Available Standards

A. Measurement Phi losophy

Regular spectral transmittance measurements provide useful information on the properties of many materials. NBS strives to provide the best possible standards and measurement services and conducts a research program to support the national requirements for this type of measurement. The current NBS effort in regular spectral transmittance is based on a primary reference laboratory with characterized instrumentation and trained personnel. The primary laboratory is responsible for realizing the national scales of spectral transmittance with a reference spectrophotometer $[1,2,3,4]$. The reference spectrophotometer is devoted to the highest accuracy measurements. Its systematic uncertainties are either calculable in the sense that an upper bound can be placed on them, or are measurable with suitable precision. The measurement precision itself is good enough to give results with a total instrumental uncertainty less than 0.0001 transmittance units in the visible region of the spectrum. A commercial spectrophotometer calibrated with master standards from the primary reference laboratory is maintained as a transfer instrument. The transfer instrument is used to calibrate Standard Reference Materials and to provide routine and special calibration and tests.

B. Description of Services

This document covers transmittance measurements listed in NBS Special Publication 250-"NBS Calibration Services Users Guide 1986-88." The items are listed in Table 1. Standard Reference Materials and a MAP service for transmittance are described in section I.C.

Regular spectral transmittance measurements over the spectral range 200 to $2500 \mathrm{~nm}$ are performed either with the reference spectrophotometer or the transfer spectrophotometer. Measurements with the reference instrument are generally made when high accuracy is needed. The transfer instrument has been characterized in terms of the reference instrument and by other tests. The transfer instrument al lows measurements to be performed quickly at a lower cost, but with an uncertainty larger than that of the reference instrument. 
Table 1

Calibration Services for Spectrophotometry

\begin{tabular}{|c|c|c|c|}
\hline $\begin{array}{l}\text { old } \\
\text { Number }\end{array}$ & $\begin{array}{l}\text { New } \\
\text { Number }\end{array}$ & Instrument & Description of Service \\
\hline $7.8 \mathrm{~A}$ & $38060 \mathrm{~S}$ & $R, T$ & $\begin{array}{l}\text { Spectrophotometric measurement services } \\
\text { (Special Tests only) Transmittance and } \\
\text { Reflectance. }\end{array}$ \\
\hline $7.8 B$ & $38010 \mathrm{C}$ & $T$ & $\begin{array}{l}\text { Spectral transmittance standard, cobalt } \\
\text { blue glass, } 40 \text { wavelengths from } 380 \text { to } 770 \mathrm{~nm}\end{array}$ \\
\hline $7.8 \mathrm{C}$ & $38020 C$ & $T$ & $\begin{array}{l}\text { Spectral transmittance standard, copper green } \\
\text { glass, } 40 \text { wavelengths from } 380 \text { to } 770 \mathrm{~nm} \text {. }\end{array}$ \\
\hline 7.80 & $38030 \mathrm{C}$ & $T$ & $\begin{array}{l}\text { Spectral transmittance standard, carbon } \\
\text { yellow glass, } 40 \text { wavelengths from } 380 \text { to } \\
770 \mathrm{~nm} \text {. }\end{array}$ \\
\hline $7.8 \mathrm{E}$ & $38040 \mathrm{C}$ & $T$ & $\begin{array}{l}\text { Spectral transmittance standard, selenium } \\
\text { orange glass, } 40 \text { wavelengths from } 380 \text { to } \\
770 \mathrm{~nm} \text {. }\end{array}$ \\
\hline $7.8 \mathrm{I}$ & $38050 \mathrm{C}$ & $T$ & $\begin{array}{l}\text { Wavelength standard, holmium oxide glass, } 240 \\
\text { to } 650 \mathrm{~nm} \text { at less than } 2 \mathrm{~nm} \text { bandpass. }\end{array}$ \\
\hline-- & $38080 \mathrm{M}$ & R & $\begin{array}{l}\text { Transmittance Measurement Assurance Program } \\
\text { (MAP). }\end{array}$ \\
\hline
\end{tabular}

*R: Reference Transmittance Spectrophotometer (RTS)

T: Transfer Spectrophotometer 
With the transfer instrument, survey spectral scans are available on a limited basis for applications where such surveys of samples are needed but high accuracy is not required. For a reduced fee, uncorrected diqital or analog data are provided without data reduction and a report of test.

C. Standard Reference Materials and Measurement Assurance Program

Transmittance, stray light, and wavelength standards are available as St andard Reference Materials (SRM) for spectrophotometer calibrations listed in Table 2. They have been calibrated by the Centers for Radiation Research and Analytical Chemistry of NBS and can be obtained from

\section{Office of Standard Reference Materials \\ National Bureau of St andards \\ Gaithersburg, Maryland 20899.}

A Transmittance Measurement Asssurance Program (MAP) service $[5,6]$ is also available (Measurement Service Number 38080M) for evaluating the entire transmittance measurement process of a laboratory. This service is provided via a set of filters called the MAP package. The MAP package consists of seven neutral density filters of nominal transmittances of $0.92,0.70,0.50$, $0.25,0.1,0.01$ and 0.001 measured at $548.5 \mathrm{~nm}$. These are used to evaluate the photometric linearity of spectrophotometers. A wavelength standard is also included in the package to aid in evaluating the wavelength scale of spectrophotometers. $[7,8,9]$ This wavelength standard is either a didymium glass filter or a holmium oxide solution for large and small bandpasses, respectively. These filters are rented to the participants. The process involves measurements by NBS followed by measurements by the participating laboratory. Finally NBS measures the package again and the data are analyzed by NBS to determine if there is any bias. It is strongly recommended that the participants obtain a set of check standards for their own use to provide continuing measurement assurance.

II. Reference Spectrophotometer for Regular Spectral Transmittance

A. Definition of "True" Regular Spectral Transmittance.

The definition of regular spectral transmittance pertinent to the NBS calibration services described in this document may be summarized as follows $[1],[10],[11]$. 
Table 2

Standard Reference Materials for Spectrophotometry

Special

Publication SRM Number

Description

\begin{tabular}{|c|c|c|}
\hline $260-51$ & 930 & Glass Filters for Spectrophotometry \\
\hline $260-51$ & 2030 & Glass Filter for Transmittance Measurements \\
\hline $260-68$ & 2031 & Metal-on-Quartz Filters for Spectrophotometry \\
\hline--- & $931 b$ & $\begin{array}{l}\text { Liquid Absorbance Standards for Ultraviolet and } \\
\text { Visible Spectrophotometry }\end{array}$ \\
\hline $260-54$ & 935 & $\begin{array}{l}\text { Crystalline Potassium Dichromate for Use as an } \\
\text { Ultraviolet Absorbance Standard }\end{array}$ \\
\hline $260-32$ & 932 & Quartz Cuvette for Spectrophotometry \\
\hline---- & 2032 & Potassium Iodide for Use as a Stray Light Standard \\
\hline--- & 2033 & $\begin{array}{l}\text { Potassium Iodide for Use as a Stray Light Standard } \\
\text { with Radiation Attenuator }\end{array}$ \\
\hline $260-66$ & $\begin{array}{l}2009 \\
2010\end{array}$ & $\begin{array}{l}\text { Didymium Glass Filters for Checking the Wavelength } \\
\text { Scale of Spectrophotometers }\end{array}$ \\
\hline $260-102$ & 2034 & $\begin{array}{l}\text { Holmium 0xide Solution for Use as a Wavelength } \\
\text { Standard in Spectrophotometry }\end{array}$ \\
\hline
\end{tabular}


Transmission is the passage (without change in wavelength) of optical radiation through transparent or translucent media. Transmission may be regular (without change in direction) or diffuse (spreading out in different directions). Transmission that is partly regular and partly diffuse is called mixed transmission.

The (total) spectral transmittance of a given medium, for a given wavelength and a given beam geometry, is defined as the ratio of the transmitted spectral radiant flux $\Phi_{\lambda, T}$ to the incident spectral radiant flux, $\phi_{\lambda}$ :

$$
T_{t}\left(\lambda, \theta^{\prime}\right)=\Phi_{\lambda, T^{T}} \Phi_{\lambda} \text {. }
$$

Where mixed transmission occurs, the total spectral transmittance can be divided into two parts corresponding to the two modes of transmission defined above:

$$
T_{t}\left(\lambda, \theta^{\prime}\right)=T_{r}\left(\lambda, \theta^{\prime}\right)+T_{d}\left(\lambda, \theta^{\prime}\right),
$$

where $T_{r}\left(\lambda \theta^{\prime}\right)$ is the regular spectral transmittance of the medium and $T_{d}\left(\lambda, \theta^{\prime}\right)$ is the diffuse spectral transmittance. Only the former will be discussed further, denoting it from now on by $T\left(\lambda, \theta^{\prime}\right)$ without the subscript ' $r$ ' in equation (2). See Figure 1.

Transmittance, as defined above, is not a well-defined property of a transmitting sample. It depends, not only on the material parameters of the sample, but also on the degree of collimation or convergence of the incident light, its polarization, and degree of coherence. Thus it cannot serve as a meaningful quantity for accurate calibrations unless constraints are imposed on its measurement so that the ratio in equation (1) is reduced to the limiting form of a "true" transmittance that depends only on the properties of the sample.

For the most commonly encountered type of a transmitting sample, a plane-parallel absorbing filter, this true regular spectral transmittance can be defined as follows. Referring to figure 1, consider a perfectly monochromatic, plane-polarized, plane wave of wavelength $\lambda$ to be incident on a perfectly plane parallel slab of infinite extent and thickness $t$, with all media both isotropic and homogeneous, and the initial and final media dielectric 


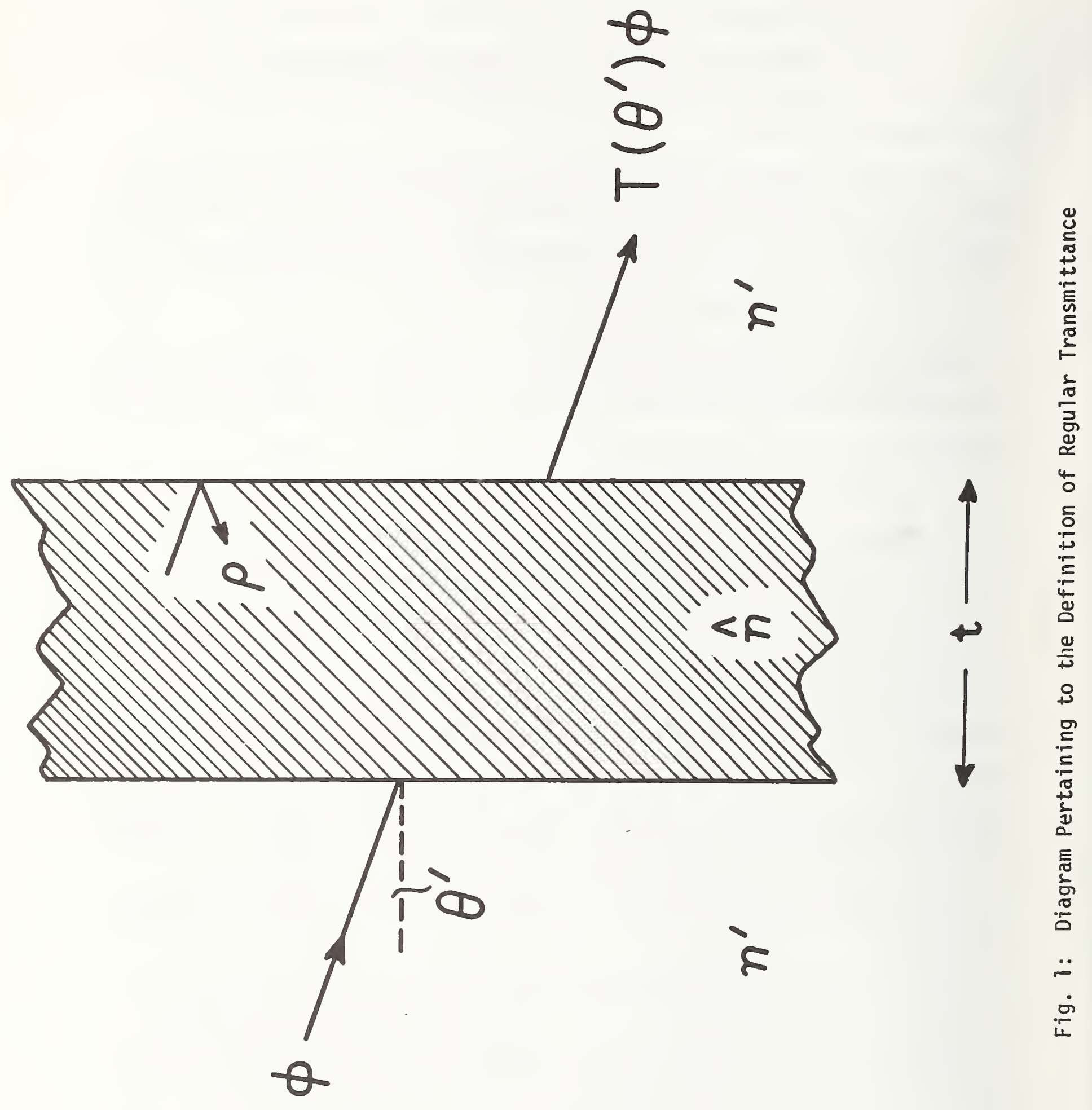


and the same. Let $\hat{n}=n(1+i k)$ be the complex index of refraction of the slab medium, $n^{\prime}$ the index of refraction of the initial and final media, and $\theta^{\prime}$ the angle of incidence. Under these conditions, the regular spectral reflectance of the slab is given by:

$$
T\left(\lambda, \theta^{\prime}\right)=\left|\frac{\left(1-\hat{r}^{2}\right) e^{i \beta}}{1-\hat{r}^{2} e^{2 i \beta}}\right|^{2}
$$

where $\hat{r}$ is the complex Fresnel coefficient of amplitude reflectance at the first boundary, and $\beta$ is defined as

$$
\beta=(2 \pi / \lambda) t \hat{n} \cos \hat{\theta} \text {. }
$$

For S-polarization,

$$
\hat{r}=\frac{n^{\prime} \cos \theta^{\prime}-\hat{n} \cos \hat{\theta}}{n^{\prime} \cos \theta^{\prime}+\hat{n} \cos \hat{\theta}}=\hat{r}_{S}\left(\theta^{\prime}\right)
$$

and for P-polarization,

$$
\hat{r}=\frac{\hat{n} \cos \theta^{\prime}-n^{\prime} \cos \hat{\theta}}{\hat{n} \cos \theta^{\prime}+n^{\prime} \cos \hat{\theta}}=\hat{r}_{p}\left(\theta^{\prime}\right) \text {, }
$$

where $\hat{\theta}$ is complex and is defined by Snell's law

$$
\sin \hat{\theta}=\left(n^{\prime} \sin \theta^{\prime}\right) / \hat{n},
$$

Equations $(3 a-e)$ show the above mentioned dependence of transmittance on beam geometry $\left(\theta^{\prime}\right)$ and polarization $(\hat{r})$. Because of this dependence, the transmittance $T\left(\lambda, \theta^{\prime}\right)$ of a given sample is an instrument-dependent quantity that can differ for different angles of incidence and/or states of polarization of the incident light. The predominant effect of angles of incidence other than $0^{\circ}$ is a decrease of internal transmittance due to increased path lengths in filters tilted with respect to the optical axis or illuminated by focussed incident light of low f-number. The effect of polarization is due to the difference of the Fresnel reflectances $\hat{r}$ for $S$ and $P$ polarized light and causes further angular variations of transmittance. It also introduces a dependence of transmittance on the state of polarization of the incident light, so that a non-polarizing filter may exhibit an apparent, instrumentdependent dichroism.

The dependence of transmittance on the coherence of the incident light is apparent from the exponential functions in equation ( $3 a)$, which contain a 
rapidly oscillating interference term depending on $(t / \lambda)$ in addition to the attenuation term that determines the absorption of the filter as a function of the attenuation coefficient $k$ and filter thickness $t$. As a consequence, the transmittance $T\left(\lambda, \theta^{\prime}\right)$ can oscillate rapidly when the wavelength is varied. Since the above equations were derived for the idealized case of perfectly coherent light, this periodic modulation of transmittance is seldom noticed in practical spectrophotometry. However, it is not always negligible and may cause variations of transmittance with wavelength, bandwidth, beam geometry, and other instrumental parameters that affect the degree of coherence of the light.

All of these instrumental effects are eliminated when transmittance is measured at normal incidence $\left(\theta^{\prime}=0\right)$ and under conditions that interference effects are eliminated, so that equations (3a-e) are reduced to

$$
\tau \equiv \overline{T(\lambda, 0)}=\frac{(1-r)^{2} \tau_{i}}{1-r^{2} \tau_{i}{ }^{2}},
$$

where

$$
r=\left|\hat{r}_{s}(0)\right|^{2}=\left|\hat{r}_{p}(0)\right|^{2}=\left|\frac{n^{\prime}-\hat{n}}{n^{\prime}+\hat{n}}\right|^{2}
$$

is the energy reflectance of the filter surfaces for normal incidence and either state of polarization, and

$$
\tau_{i}=\exp (-4 \pi n k t / \lambda)
$$

is the normal internal transmittance of the filter. This averaged normalincidence transmittance $\tau=\overline{T(\lambda, 0)}$ is a function of the filter parameters $n$, $k$, and $t$ only, and may therefore be identified as the above mentioned "true" regular spectral transmittance of the filter. As described in the following, the NBS reference spectrophotometer for regular spectral transmittance has been designed to measure this "true" transmittance $\tau$ with high accuracy. Samples are placed normal to the axis of a collimated beam to avoid obliquity and polarization effects (although measurements for other than normal incidence can be made, if desired). Interference effects, if detectable, are measured and then averaged to determine the "true" transmittance. Diffraction effects are eliminated by using the same limiting aperture for the sample and clear-space measurements so that these effects are the same for both measurements and cancel, yielding the "true" transmittance $\tau$ in spite of the finite aperture size. The "true" transmittance as defined is measured relative to air with density and humidity effects being negligible. 


\section{B. Instrument at ion}

The NBS reference transmittance spectrophotometer (RTS) has been described in detail in previous publications $[1,2,3,4]$. A brief description of the instrument, practical suggestions for its use, and some of its limitations will be given in this section.

1. Basic Instrument.

The major instrumental features of the RTS are a stable source, mirror optics, circular entrance and exit apertures of the monochromator (instead of slits), detector with averaging sphere, and linear electronics. By using off-axis parabolic mirrors, accurate and achromatic collimation and focusing of the light and absence of inter-reflections between sample and optics are achieved. The averaging sphere [12] is efficient and eliminates errors due to small displacement of the light beam by the sample. A current-tofrequency converter integrates the signal over time and provides an accurate measure of the light flux incident on the detector.

The basic instrument as it is configured for the ultraviolet and visible is shown in Fig. 2. A $5 \mathrm{~mW}$ He-Ne laser is used to align the optics and to align samples for measurement. Atomic line sources are used to calibrate the wavelength scale. A 0.4 A deuterium source with a $2 \mathrm{~mm}$ by $4 \mathrm{~mm}$ aperture is used in the ultraviolet, and a 6V-18A (108 watt) tungsten strip lamp is used in the visible. Both sources are used in series with a $0.1 \Omega$ shunt resistor for constant current regulation. The collimating mirror of the fore optics is a $15^{\circ}$ off-axis parabola of $177 \mathrm{~mm}$ focal length. The focusing mirror is a $8.5^{\circ}$ off-axis parabola of $195 \mathrm{~mm}$ focal length. The state of polarization of the beam is not altered by its passage through the monochromator. A GlanThompson prism is used to attenuate the beam as described below. A second Glan-Thompson prism produces a defined state of polarization.

The predisperser utilizes a quartz prism in an Ebert mount with a $1 \mathrm{~mm}$ entrance slit. It has $15.2 \mathrm{~cm}$ focal length collimating and focusing mirrors and a horizontal aperture ratio of $f / 6$.

The main monochromator is a commercial $1 \mathrm{~m}$ Czerny-Turner system with an effective aperture of $\mathrm{f} / 8.7$. Four gratings are provided for this monochromator, each $102 \mathrm{~mm}$ by $102 \mathrm{~mm}$. They have 1200 grooves $/ \mathrm{mm}$ blazed at $500 \mathrm{~nm}, 600$ groves/mm blazed at $200 \mathrm{~nm}, 150$ grooves/mm blazed at $800 \mathrm{~nm}$, and 150 


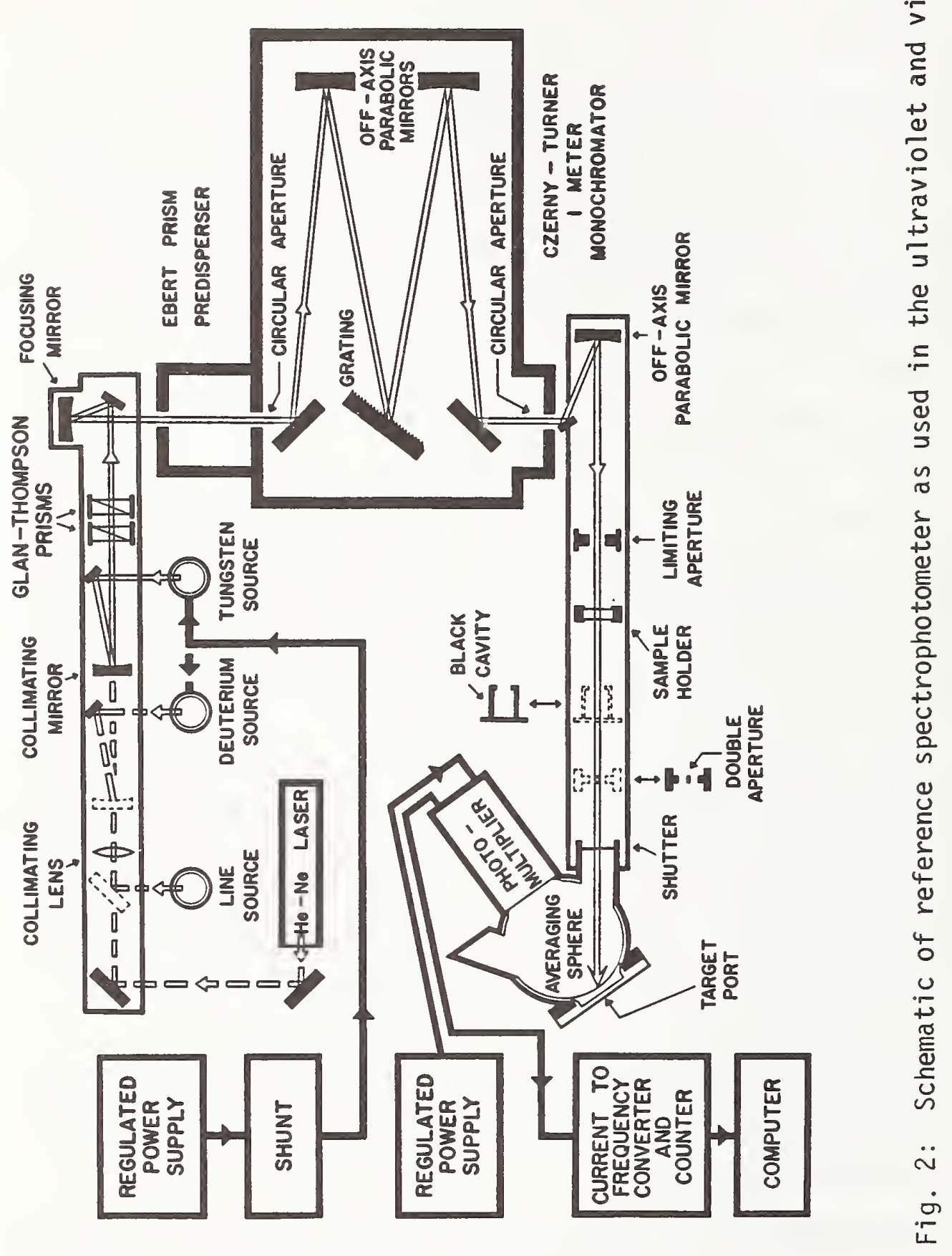


grooves/mm blazed at $1250 \mathrm{~nm}$ respectively. The monochromator collimating and focusing mirrors are off-axis parabolas, paraboloidal to within 0.1 fringe in green light and free of zones. These mirrors can be moved along a rail and adjusted by micrometer screws.

The entrance and exit apertures of the monochromator are circular holes with diameters selectable as $.250 \mathrm{~mm}, .500 \mathrm{~mm}, .750 \mathrm{~mm}$, or $1 \mathrm{~mm}$. These four apertures can be rotated alternately into position. The exit aperture thus approximates a point source. Collimation of the monochromator output is achieved by an $8.5^{\circ}$ off-axis parabolic mirror with $195 \mathrm{~mm}$ focal length. The degree of collimation for the $1 \mathrm{~mm}$ monochromator exit aperture is about $1 / 400$ radian.

A limiting aperture defines the size and shape of the light spot at the sample. The sample holder is a wheel accommodating up to 3 samples, or a sliding holder accommodating one filter. The latter accomodates odd sizes and shapes of samples and can also be temperature controlled. A pneumatically driven black cavity is used to block the beam when measuring the dark signal. A double aperture linearity tester (described in Section II.C.2) can also be inserted into the beam. The averaging sphere is mounted in front of the photomultiplier [12].

The photomultiplier is an 11-stage, end-on tube with S-20 response. Its dynode chain is a linear potted resistor chain with a Zener diode between cathode and the first dynode. Its high voltage power supply is regulated to $0.001 \%$.

The anode current is measured by means of a Taylor-type [13] current-tofrequency converter. This converter, together with a high accuracy counter used with $10-\mathrm{sec}$ integration time, was found to be linear to better than $0.01 \%$ by measuring the currents produced in precision resistors by a calibrated voltage source of $0.01 \%$ accuracy. By the same method, the current-to-frequency converter and counter were found to be precise to at least 1 part in 45,000 in the current ranges normally used.

Fig. 3 shows the instrument as configured for the near infrared. A 500 $W$ tunqsten lamp in a water cooled jacket is used as the source. The quartz lenses are inserted in the fore optics to focus the beam at a chopper. Only one polarizer is used to maximize throughput. The signal is amplified by a 


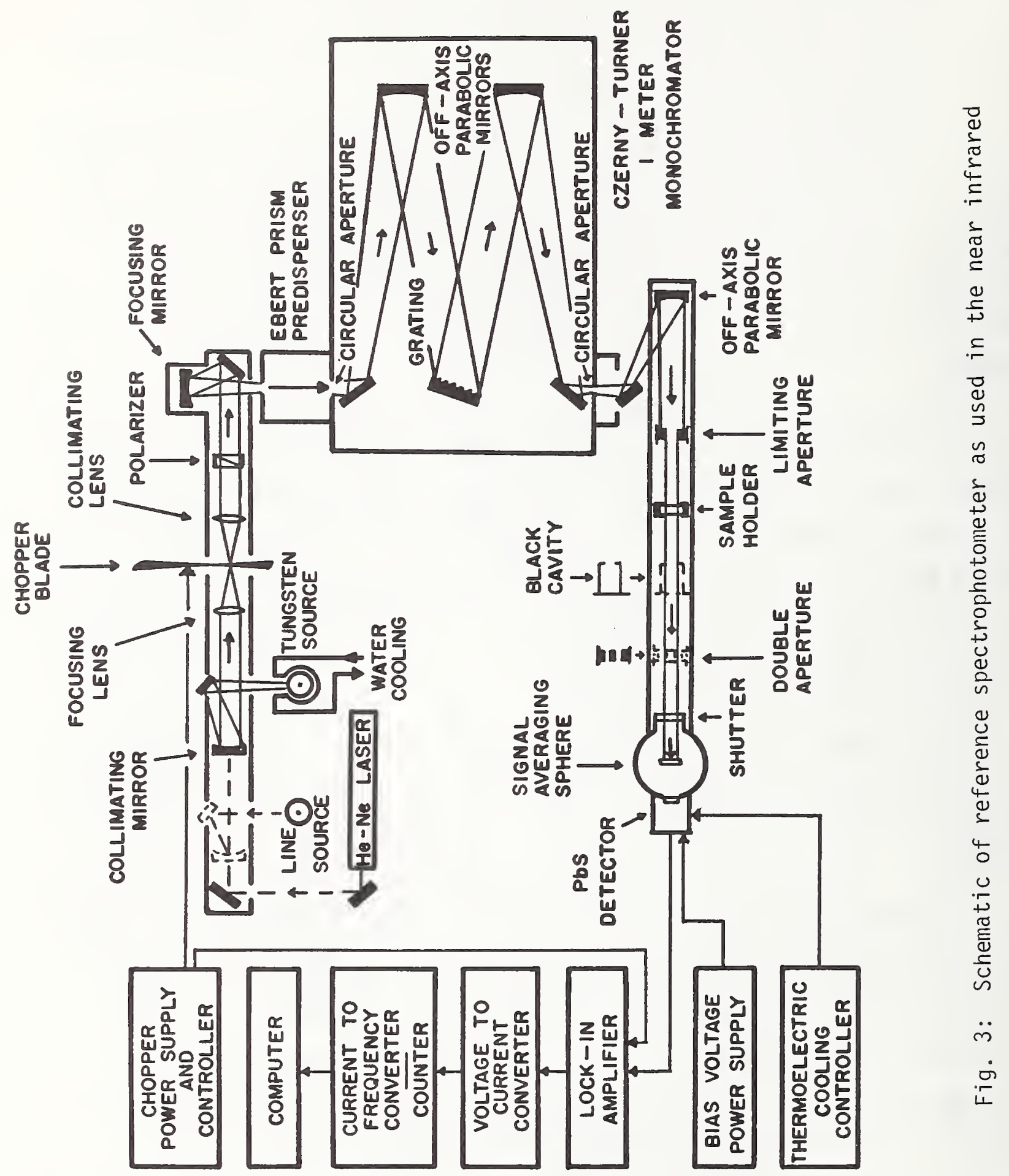


lock-in amplifier where voltage output is converted to a current. Otherwise, the instrument is operated in the same manner as in the ultraviolet and visible.

\section{Optical Alignment}

The optical alignment of the RTS is based on pre-determined values of the relative spacing of optical elements, their focal lengths, and required angles of incidence. Using the He-Ne alignment laser, the optic axis is established by placing masks with small central holes over the collimating and focussing mirrors of the monochromator, and then aligning the mirrors external to the monochromator so that the distance of the laser beam from the table surface is constant everywhere.

\section{Automation}

a. Hardware.

The wavelength drive of the monochromator and the two polarizers are equipped with stepping motors. The sliding sample holder and all shutters are operated pneumatically. The wheel is operated by a synchronous motor with latching relays. A dedicated microcomputer with interface boards incorporating relays, stepping motor drivers, and input-output ports is used. An analog feedback circuit controls the light level by rotating the polarizer nearest to the source. The light level can be adjusted to $100 \%$, $80 \%, 60 \%, 40 \%$, and $20 \%$ of full scale when measuring transmittance or linearity. Following manual sample insertion and alignment, all measurement steps are performed automatically.

\section{b. Software.}

The primary computer program allows choice of sample holder, number of samples, planes of polarization, and wavelength scans at equally spaced intervals or arbitrary specific wavelengths. An abbreviated version of the program allows faster data acquisition with larger statistical uncertainty. A statistical analys is program computes the transmittance and its standard deviation. Additional software is available for wavelength calibrations by determining the centroid of the monochromator slit function, for linearity measurements, stability tests, and stray light measurements. 
4. Measurement Capabilities and Required Sample Properties

The following information is provided to acquaint users with the types of measurements that can be performed on the RTS. Also listed are the required properties of user-submitted samples that can be accepted for these measurements. Under each heading, standard procedures are described first and acceptable alternatives (if any) are stated in parentheses. Where appropriate, suggestions are made for the preparation of samples prior to submission to NBS.

\section{a. Identification.}

Each filter submitted must have permanent identification markings which distinguish it from other similar filters. (We can inscribe identifying markings on a filter with a diamond stylus.) Generally, we will not measure an unmarked sample.

\section{b. Stability.}

Special filters are not usually tested for stability. The stability of each filter should be investigated over a period of time comparable to that for which the measured values are intended to be used. If the filter is to be a permanent standard, it should be submitted for remeasurement on the RTS at suitable, progressively longer intervals of time until its stability has been established.

\section{c. Cleaning.}

The filter should be cleaned in advance and shipped in a suitable protective container. (At additional cost, a filter will be cleaned according to the owners' specific instructions. However, we will then postpone the measurement until the filter has stabilized.) For best results, a regular cleaning routine should be established and each stability test should involve prior cleaning following this procedure. For glass filters, the cleaning should involve degreasing if necessary, washing with mild soap or mild, non-fluorescing detergent, and/or isopropyl alcohol, and rinsing with distilled water. Harsh acidic or basic cleaning agents should be avoided, since they disturb oxide layers and other persistent surface films which can take a long time to restabilize. For exposed metal film filters, the instructions of the manufacturer should be followed. Great care should be 
taken to avoid contact with the metal film, since scratches and other marks can greatly degrade such a filter.

d. Measured Area.

The usual procedure for the visible spectral region is to measure an average transmittance over a central area which is smaller than the filter, falls within a circle of $16 \mathrm{~mm}$ diameter, and has an area larger than approximately $25 \mathrm{~mm}^{2}$. The latter requirement ensures signal-to-noise ratios adequate for high-accuracy measurements. In the ultraviolet, spot diameters of 10 to $16 \mathrm{~mm}$ are normally used. In the near infrared, a spot diameter of $16 \mathrm{~mm}$ is normally used. Usually, we try to measure the same area as when the filter is in use. At the ends of the wavelength ranges of the RTS larger spot sizes may be preferable in order to reduce the influence of noise.

e. Uniformity.

Filters are not routinely checked for uniformity. (We can perform uniformity tests at a charge for additional mounting and alignment along with one additional measurement for each wavelength and each filter displacement required. However, such tests are not as appropriate as one made by the user on his own instrument under the conditions of use.) Users can check for non-uniform transmittance of filters by observing the effects of displacing them perpendicular to the incident beam. Because even within a given production run some filters can be much more non-uniform than others, such checks can save time and cost, and should be performed on each filter before submission to NBS.

f. Polarization.

Transmittance measurements on the RTS are usually made with radiation polarized in only one direction of the electric vector. The direction of the electric vector with respect to the orientation of the filter will be stated in the report. Unless a specific orientation is requested, we will choose the orientation at our convenience. (Filters can be measured at two orientations of the electric vector without additional mounting and alignment, but the number of measurements will be doubled.) It is usually desirable that a filter does not polarize the radiation passing through it. To test whether a filter is polarization-sensitive, users should place a 
polarizer in the spectrophotometer beam along with the filter, and measure the transmittance of the combination with the filter rotated in $45^{\circ}$ increments about its normal while the polarizer remains fixed, or vice-versa. For a uniform non-polarizing filter, the measured transmittance will be the same for all orientations.

\section{g. Temperature.}

Measurements on the RTS are normally made at the ambient temperature of our laboratory. The temperature has small seasonal variations, but is constant to within $\pm 0.5^{\circ} \mathrm{C}$ near room temperature (usually $23^{\circ} \mathrm{C}$ or $25^{\circ} \mathrm{C}$ ) during a given set of measurements. It will be stated in the report. (A specia) temperature controlled filter holder can be used to measure certain sizes of filters at specified temperatures over the range $15^{\circ} \mathrm{C}$ to $35^{\circ} \mathrm{C}$ for determinations of temperature coefficients of transmittance. Such measurements are time-consuming and costly, and are only made under special arrangements.) Users should measure filters at several expected temperatures to determine if the temperature coefficients of the filters are acceptable. Since filters are usually poor heat conductors, the best way to vary the temperature of a filter is to vary the ambient temperature uniformly. This can be done by mounting the filter in a constant temperature metal box or cylinder with minimal openings for transmittance measurements. Measurements are made after the temperature of the filter has stabilized.

h. Solid Angle of Collection.

The solid angle of collection of the RTS is circular and subtends approximately .0025 sr at the filter location. This solid angle can be adjusted over the ranqe .001 sr to .01 sr at added mounting and alignment costs. For filters that scatter appreciably, the solid angle of collection must be specified for meaningful interpretations of results. The scattering of the filter can be estimated by measuring its transmittance at different positions along the path of the incident beam. If scattering is noticeable, a measurement of diffuse transmittance should be arranged.

i. Angle of Incidence.

Measurements on the RTS are made with collimated radiation incident normal to the surface of the filter. (For added cost, measurements can be made at other angles of incidence.) 
j. Filter Size.

Filters having the following common sizes can be measured on the RTS either singly or in groups of two or three:

$5.1 \mathrm{~cm} \times 5.1 \mathrm{~cm}$ square

$3 \mathrm{~cm}$ diameter circular

$1.3 \mathrm{~cm} \times 1.3 \mathrm{~cm} \times 5.7 \mathrm{~cm}$ cuvette

$1.1 \mathrm{~cm} \times 3.05 \mathrm{~cm}$ rectangle.

(0ther sizes of filters up to $10 \mathrm{~cm} \times 10 \mathrm{~cm}$ can be measured singly by special arrangement.)

k. Wavelength.

The RTS is equipped to make measurements at wavelengths from 200 to $2500 \mathrm{~nm}$ in three ranges as follows: 200 to $400 \mathrm{~nm}, 360$ to $800 \mathrm{~nm}$, and 800 to $2500 \mathrm{~nm}$. Table 3 lists the equipment used for these ranges.

1. Bandwidth.

The measurement can be made at the following nominal half-height bandwidths in nanometers:

\begin{tabular}{cl}
$\begin{array}{c}\text { Wave length Range } \\
(\mathrm{nm})\end{array}$ & \multicolumn{1}{c}{$\begin{array}{c}\text { Bandwidths } \\
(\mathrm{nm})\end{array}$} \\
$200-500$ & $1.5,1.13,0.75,0.38$ \\
$400-800$ & $1.5,1.13,0.75,0.38,0.19$ \\
$800-2500$ & 6.0
\end{tabular}

For the most accurate measurements, bandpasses of $1.5 \mathrm{~nm}$ in the $200-500 \mathrm{~nm}$ range, 0.75 and $1.50 \mathrm{~nm}$ in the $400-800$ range, and $6 \mathrm{~nm}$ in the range $800-$ 2500 result in a minimal number of measurements necessary to obtain a desired precision. Because the RTS has circular entrance and exit apertures instead of slits, the bandpass shape is not quite triangular, but it can be reqarded as such for practical purposes. (Data for large bandpasses can be synthesized from narrow-band measurements at an increased cost for additional measurements and computations. With the NBS Reference Spectrophotometer for Diffuse Transmittance and Reflectance, regular transmittance measurements with $5,10,15$, and $20 \mathrm{~nm}$ nominal bandpass can be made at slight ly higher 
Range, Source, Grating, Detector and Measurement Mode for Wavelength Ranges

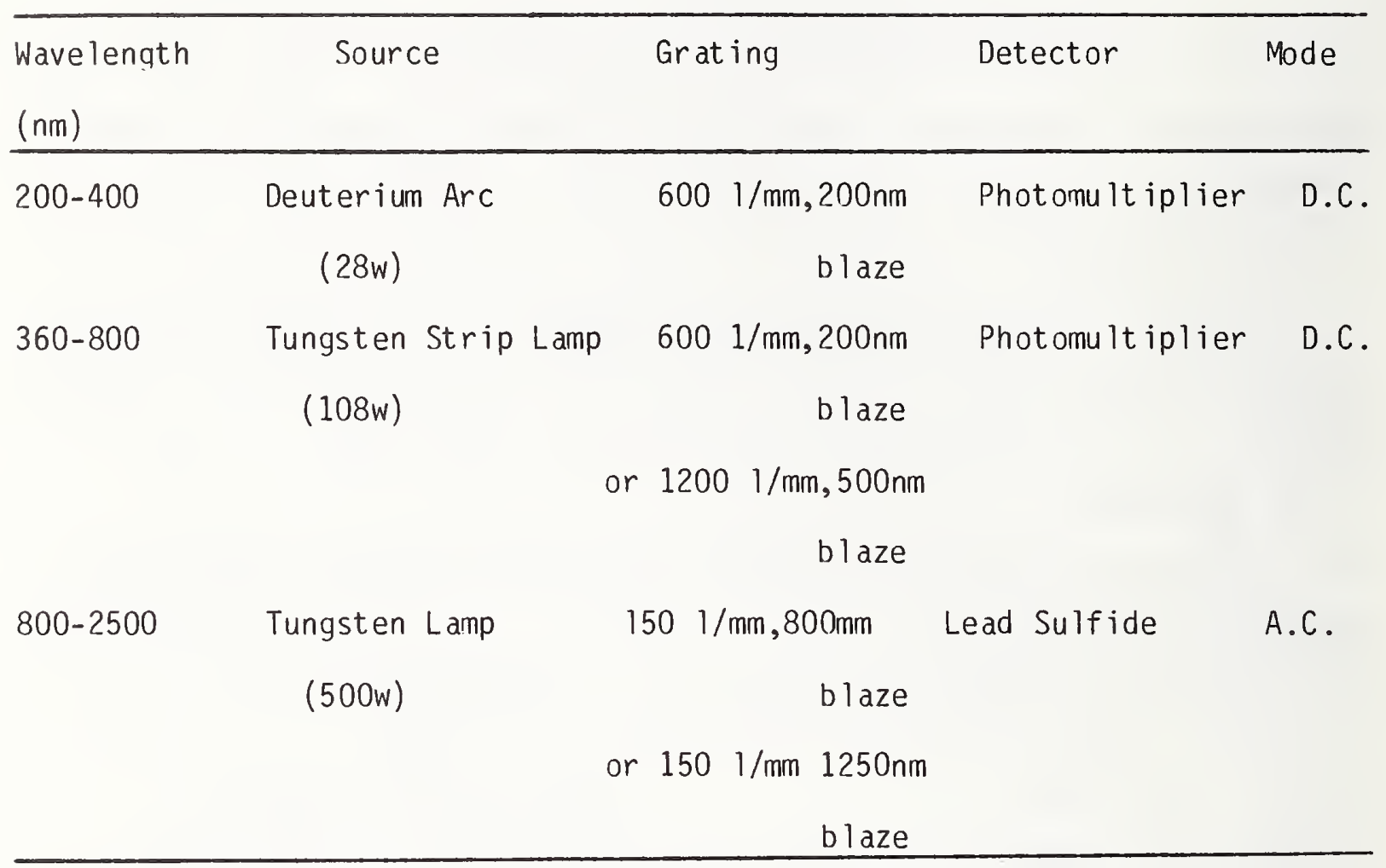


levels of uncertainty than that for measurements made with the RTS.) Unless there is a definite need for a given bandwidth, it is usually best to choose the largest bandwidth which can provide the information about the filter. For filters with strong spectral features, the bandwidth should be chosen as close as possible to that being used by the customer.

m. Transmittance Range.

The range of transmittances routinely calibrated on the RTS is 0.1 to 1.0 transmittance. Measurements below 0.1 transmittance can be made with the step-down technique described in Appendix A, page A-3. One step-down filter and an additional set of measurements is required for each order of magnitude of transmittance below 0.1. It is suggested that customers have their own step-down filters calibrated, since the cost will be the same if NBS filters are used. The step-down procedure becomes complicated for spectrally non-neutral filters and more measurements are required in this case.

\section{Instrument Calibration and Internal Quality Control}

Since even the best available transmittance standards may change over time $[14,15]$, the RTS serves as a reference for the accuracy and stability of the NBS scale of regular spectral transmittance. For this purpose, the RTS is monitored with respect to four parameters: wavelength accuracy, linearity of the photometric scale, stability of source and detection system, and stray radiant energy.

\section{Wave length Accuracy}

The wavelength scale of the RTS is checked periodically to ensure wavelength accuracy. Wavelength calibration is accomplished by means of atomic line sources in the ultraviolet, visible, and most of the near infrared. At the longest wavelengths in the near infrared, absorption bands are used. The atomic emission lines used to calibrate the wavelength scale in the ultraviolet and visible spectrum are listed in Table 4. The emission lines and absorption bands for the near infrared spectrum used are listed in Table 5. An example of a wavelength correction curve is shown in Fig. 4. The coefficients for wavelength corrections of transmittance measurements are stored in computer memory. The systematic uncertainty of the corrected wavelengths is $0.04 \mathrm{~nm}$ in the ultraviolet and visible [3] and $0.26 \mathrm{~nm}$ in the near infrared. [4] 
Wavelengths of Atomic Emission Lines Used for Wavelength Calibrations in the UV and Visible Spectrum

a. Lines used with the $.25 \mathrm{~mm}$ apertures

\begin{tabular}{|c|c|c|c|}
\hline Element & $\begin{array}{c}\text { Wave length } \\
(\mathrm{nm})\end{array}$ & Element & $\begin{array}{l}\text { Wave length } \\
\qquad(\mathrm{nm})\end{array}$ \\
\hline Cs & $\begin{array}{l}455.536 \\
459.318\end{array}$ & $\mathrm{He}$ & $\begin{array}{l}388.865 \\
501.568 \\
587.562 \\
667.815\end{array}$ \\
\hline $\mathrm{Rb}$ & $\begin{array}{l}420.185 \\
421.556 \\
780.023 \\
794.760\end{array}$ & $\mathrm{Ne}$ & $\begin{array}{l}640.225 \\
692.947 \\
724.517\end{array}$ \\
\hline $\mathrm{Hg}$ & $\begin{array}{l}275.278 \\
296.728 \\
334.148 \\
404.657 \\
407.784 \\
435.834 \\
491.604 \\
546.075 \\
576.960 \\
579.066\end{array}$ & $\mathrm{Zn}$ & $\begin{array}{l}467.816 \\
479.992 \\
508.582 \\
643.847 \\
\\
213.856\end{array}$ \\
\hline
\end{tabular}

b. Lines used with the $1 \mathrm{~mm}$ apertures

\begin{tabular}{cc} 
Element & Wavelength \\
\hline $\mathrm{Zn}$ & 213.856 \\
$\mathrm{He}$ & 388.865 \\
$\mathrm{Hg}$ & 546.075 \\
$\mathrm{Rb}$ & 780.023
\end{tabular}




\section{Table 5}

Wavelengths of Atomic Emission Lines and Molecular Absorption Bands Used for Wavelength Calibrations in the Near IR Spectrum

\begin{tabular}{ccl}
\hline Element or Chemical & $(\mathrm{nm})$ & Type of Spectra \\
\hline $\mathrm{Rb}$ & 780.02 & Emission Line \\
$\mathrm{Rb}$ & 794.76 & Emission Line \\
$\mathrm{Hg}$ & 1013.98 & Emission Line \\
$\mathrm{Hg}$ & 1128.70 & Emission Line \\
$\mathrm{Hg}$ & 1529.52 & Emission Line \\
$\mathrm{Hg}$ & 1692.1 & Emission Line \\
$\mathrm{Hg}$ & 1970.1 & Emission Line \\
1,2,4-trichlorobenzene & 2152.6 & Absorpton Band \\
1,2,4-trichlorobenzene & 2437.4 & Absorpton Band \\
\hline
\end{tabular}




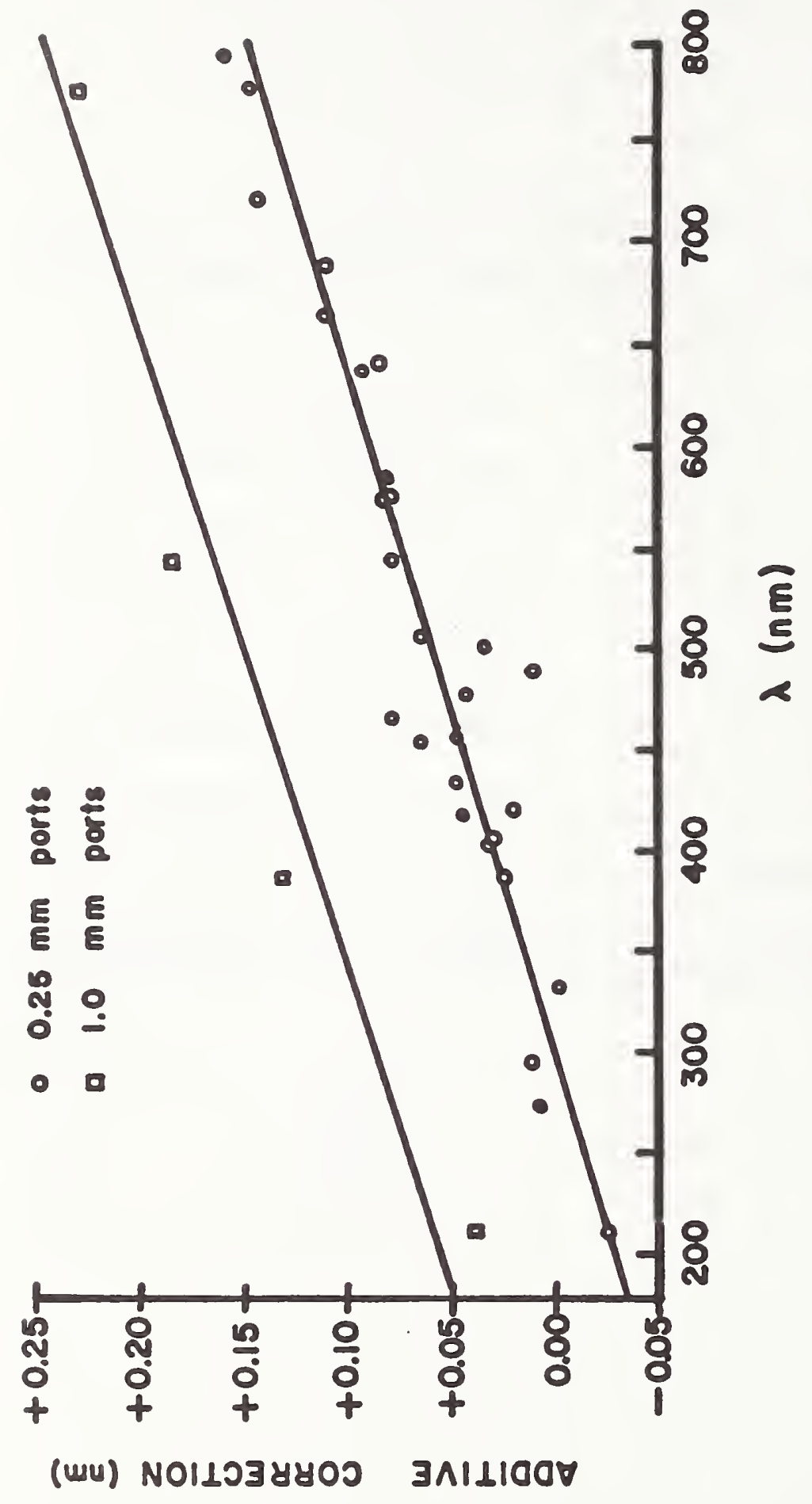

ป 
These uncertainties are upper bounds and may be regarded as having a $99.7 \%$ confidence level (3o equivalent). All upper bounds in this publication will be equivalent to $3 \sigma$ uncertainties.

2. Linearity of the Photometric Scale.

All measurements with the RTS are corrected for nonlinearity of the detector and electronics. The non-linearity is measured using a double aperture method devised by Mielenz and Eckerle [16]. A double-aperture linearity tester with two $5-\mathrm{mm}$ beveled circular apertures separated by $10 \mathrm{~mm}$ is placed in the collimated beam in the sample compartment. These apertures can be opened and closed by pneumatically operated shutters controlled by two solenoids located remote from the detector.

Then the following readings are taken: $I(A)$, the intensity with one aperture open; $I(B)$, the reading with the other aperture open; and $I(A+B)$, the reading with both apertures open. $I(A)$ is approximately equal to $I(B)$. Then if the quantity

$$
\sigma^{\prime}(A, B)=\frac{I(A+B)}{I(A)+I(B)}-1 \text {, }
$$

is greater than 0.0001 , a correction term is derived. The measurements of $I(A), I(B)$, and $I(A+B)$ are done in a time-symmetrical sequence so as to compensate for linear drifts of the detection system(See Section D.5.b.). The linearity test is automated by means of the data acquisition and control system.

The non-linearity corrections for transmittance measurements in the UV and visible, using the photomultiplier tube on the $3 \times 10^{-7} \mathrm{~A}$ scale, is a few parts in $10^{4}$ for a transmittance approximately 0.5 (see Figure 5 ). On the 3 $x 10^{-8}$ A scale the correction is zero with an uncertainty of a few parts in $10^{4}$. The non-linearity of the photomultiplier tube has been monitored since 1972 and has shown no significant changes over the years.

Experience with the PbS detector used in the near ir is still limited, but data taken indicate that its non-linearity does not exceed the standard deviation of approximately $1 \times 10^{-4}$ with which it $c$ an be measured. No correction is applied in this case. 


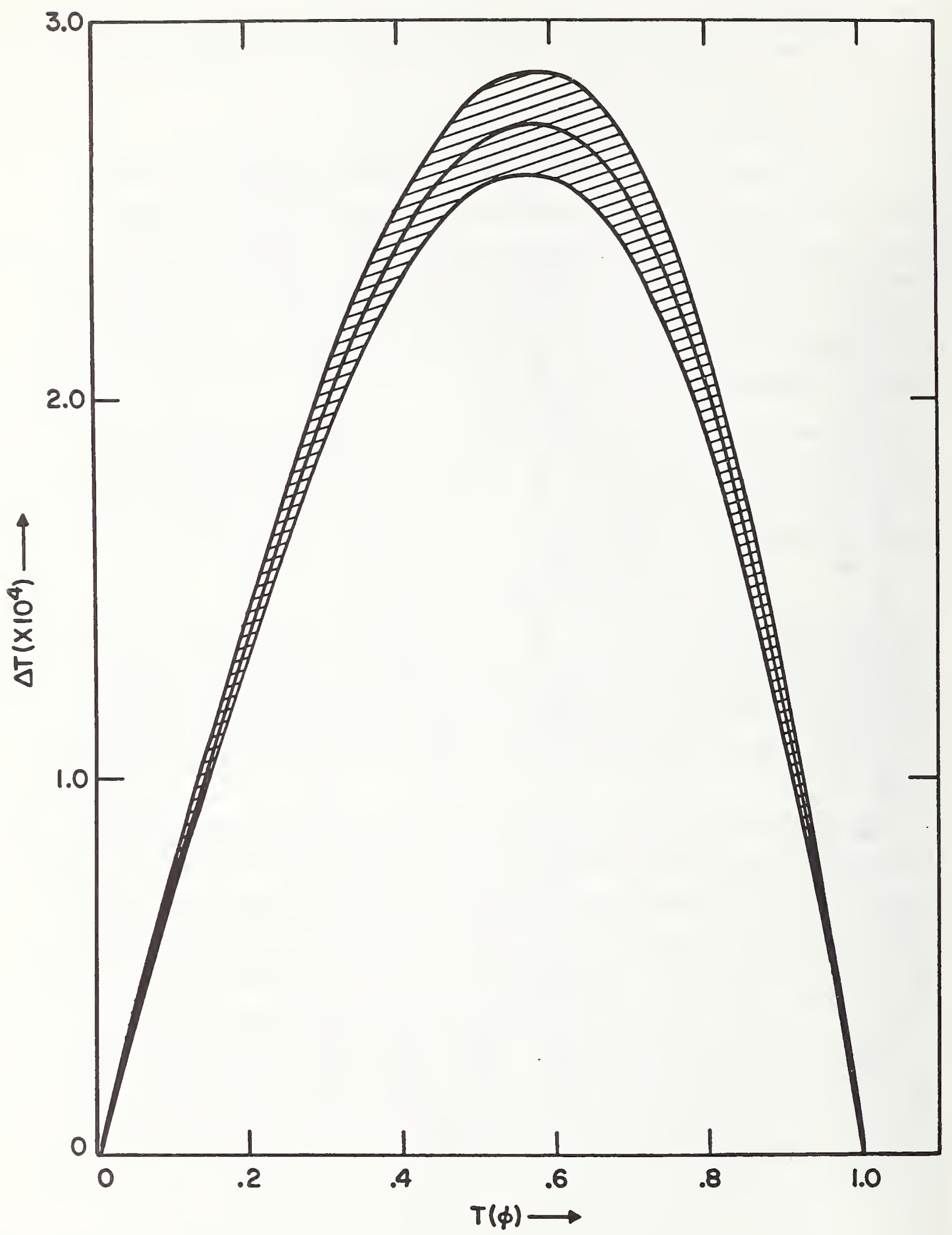

Fig. 5: Additive correction, $\Delta T$, versus transmittance $T(\phi)$. The shaded area represents \pm 1 standard deviation. 
3. Stability of Source and Detection System

The stability required of the RTS is such that a filter with transmittance 0.5 can be measured with a standard deviation of 0.00005 . Two sources of instability have been found to date. One is the photomultiplier power supply, and more often, the tungsten strip light source or its power supply. The source of the instability is determined by putting a stable betalight (beta particle activated phosphor) in front of the detection system. If the detection system is found to be stable, the instability will be due to the source or its power supply.

\section{Stray Radiant Energy}

Stray light may arise from two causes. One is room light penetrating the instrument enclosure. It can be detected by a difference in signal with the photomultiplier shutter open and closed.

The other is light of other than the desired wavelength being passed by the optical system. This stray radiant power is more difficult to detect. Order of magnitude estimates for this stray radiant power can be obtained by the selection of suitable sharp absorption filters, both liquid and solid, following an ASTM Method [17]. Stray light is of the order $10^{-5}$ to $10^{-6}[2,3,4]$ of full scale reading.

D. Measurement Procedure.

Since the instrument is automated and has a dedicated microcomputer, the RTS can perform most measurements with minimal requirements for manual operations and without errors that they can cause. A change in sample or a change in photomultiplier voltage are examples which require manual action.

The measurement procedures are generally straightforward. Measurements involving unusual filter sizes, angles of incidence, or scattering temperature control, require special attention.

1. Sample Preparation.

First, it must be determined whether a filter needs cleaning as described in Section II.B.4.C above. If it must be determined whether a filter has changed since a previous measurement, the filter should not be cleaned but only lightly brushed with a clean camel hair brush to remove dust particles. 


\section{Sample Alignment.}

The alignment laser is used to aid in positioning the samples by means of three alignment screws on the sample wheel or slider. With the wheel, samples are usually aligned normal to the beam, so that the laser light is reflected back into the exit aperture of the monochromator. Angles of incidence up to approximately $4^{\circ}$ from normal are also possible with the wheel. For large angles the slider, which is mounted on a rotary table, is more convenient. The maximum angle of incidence which may be used depends on the size and shape of the sample. A vernier on the rotary table is used to determine the angle of rotation.

3. Sample Uniformity.

Even the best samples exhibit some non-uniformity. The wheel and slider have vertical or horizontal translation stages which may be used manually for uniformity checks at one or two wavelengths. For uniformity checks at a large number of positions or many wavelengths, a special automated $x-y$ translation device can be used.

4. Polarization

High-quality filters should not exhibit detectable polarization effects at normal incidence. For oblique angles of incidence, the transmittance will depend on the plane of polarization ( $s$ or p polarization) because of Fresnel's laws. It is usually advisable to check for polarization effects at one or two wavelengths.

5. Data Acquisition and Reduction

a. Transmittance [3]

Transmittance data are taken in a manner such that linear drifts of the system are eliminated. The method of data acquisition and reduction for three filters is outlined below as an example. If 0 is the dark reading (shutter closed); $I_{o j}$ is the $j$ th reading of the clear-space signal; $I_{l_{j}}, I_{2} j$, and $I_{3}$ are the $j$ th readings of filters 1,2 , and 3 ; and each of these readings $I_{i j}$ is taken at time $t_{i j}$, the measurement sequence is: $0 I_{01} 0 I_{11}$ $\begin{array}{llllllllllllllllllllllllllll}0 & I_{21} & 0 & I_{31} & 0 & I_{02} & 0 & I_{32} & 0 & I_{22} & 0 & I_{12} & 0 & I_{03} & 0 & I_{13} & 0 & I_{23} & 0 & I_{33} 0 & I_{04} & 0 & I_{34} & 0 & I_{24}\end{array}$ $\begin{array}{lllll}0 & I_{14} & 0 & I_{05} & 0\end{array}$ 
The dark readings are interpolated in time and subtracted from each clearspace or filter reading before any further analysis.

$$
\text { Let } t_{0}=\frac{t_{01}+t_{05}}{2}
$$

be the time half-way between times $t_{01}$ and $t_{05}$ at which readings $I_{01}$ and $I_{05}$ are taken. To reduce the number of digits for computation, a new time scale $t_{i j}$ is used:

$$
t_{i j}^{\prime}=t_{i j}-t_{0}
$$

For any fitted straight line through readings $I_{i j}$, for a specific value of $i$ if $m^{\prime}$ is the normalized slope of the fitted line ( $m^{\prime} I_{j}^{\prime}$ is the slope) and $I_{j}^{\prime}$ is the value at $t_{0}$ on this line, the predicted value for the reading $I_{i j}$ will be

$$
I_{i j}^{\prime}=\left(m^{\prime} t_{i j}^{\prime}+1\right) I_{i}^{\prime}
$$

This data reduction method utilizes all seventeen readings $I_{i j}$ to obtain a common and more accurate $\mathrm{m}^{\prime}$ and in turn $I_{j}^{\prime}$ with the least square fitting and iteration techniques to minimize the sample variance $s^{2}$ of all the $I_{i j}$. For a given $m^{\prime}$ and set of $I_{j}^{\prime}$ values the sample variance $s^{2}$ is

$$
\begin{aligned}
& s^{2}=\Sigma_{i}\left(N_{i}-2\right)^{-1} \Sigma_{j}\left(I_{i j}^{\prime}-I_{i j}\right)^{2} \\
& =\Sigma_{i}\left(N_{i}-2\right)^{-1} \Sigma_{j}\left[\left(m^{\prime} t_{i j}^{\prime}+1\right) I_{j}^{\prime}-I_{i j}\right]^{2}
\end{aligned}
$$

The logical initial $\mathrm{m}^{\prime}$ and $I_{j}^{\prime}$ to be selected to calculate $s^{2}$ are

$$
\begin{aligned}
m^{\prime} & =0, \\
I_{i}^{\prime} & =\frac{1}{N_{i}} \quad \Sigma_{j} I_{i j},
\end{aligned}
$$

where $N_{i}$ is the maximum number of readings for a given $i$. The new $m^{\prime}$ is calculated from $m^{\prime}=\frac{\Sigma_{j}\left(N_{i}-2\right)^{-1} \Sigma_{j}\left(I_{i j}-I_{j}^{\prime}\right) t_{i j}^{\prime} I_{i}^{\prime}}{\Sigma_{i}\left(N_{i}-2\right)^{-1} \Sigma_{j}\left(t_{i j}^{\prime}\right)^{2}\left(I_{j}^{\prime}\right)^{2}}$.

The new $I_{j}^{\prime}$ is

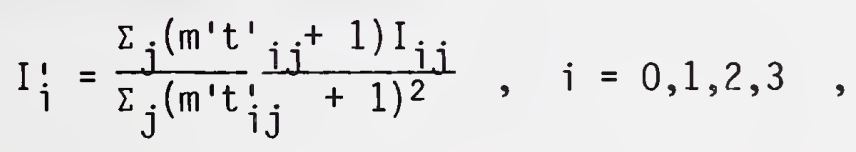


and a new $s^{2}$ is calculated using Eq. (9b). This process is repeated until $s^{2}$ is sufficiently small $\left(10^{-11}\right)$. The I''s giving this $s^{2}$ are used to calculate the transmittance $\tau_{n}$ for the $n$th filter.

$$
\tau_{n}=\frac{I_{n}^{\prime}}{I_{0}^{1}}, n=1,2,3
$$

The sample standard deviation $s_{n}$ of $\tau_{n}$ is

$$
s_{n}=\tau_{n}\left[\frac{\left(s_{n}\right)^{2}}{\left(I_{n}^{\prime}\right)^{2}}+\frac{\left(s_{0}\right)^{2}}{\left(I_{0}^{\prime}\right)^{2}}\right]^{1 / 2} \text {, }
$$

where $s_{i}^{2}=\frac{\Sigma_{j}\left(I_{i j}-I_{i j}\right)^{2}}{N_{j}\left(N_{j}-2\right)}, i=0,1,2,3$

is the variance of the $I^{\prime}$ for a given $i$.

b. Linearity [16]

Data for the linearity measurements $c$ an be taken at equal time intervals. The signal currents thus obtained generally drifted in time, at a rate of typically - $3 \mathrm{ppm} / \mathrm{min}$ and exhibited random fluctuations superimposed upon this drift. Since all quantities measured with a spectrophotometer are ratios, such as $r=I / J$, the drift is of no concern provided it is linear in time and provided that a series of data,

$$
\text { I , J , I , ... J, I, }
$$

is taken at fixed time intervals. Then, the influence of the drift is eliminated when $r$ is expressed as the $r a t i o, r=\bar{I} / \bar{J}$, of the averaged values of $I$ and $J$. Under these conditions the quantity affecting the precision of measurement is the standard deviation,

$$
\left.d I=\sum_{\nu=1}^{n}\left[I_{\nu}-I(\nu t)\right]^{2} /(n-1)\right]^{1 / 2} \text {, }
$$

where

$$
I_{1}, I_{2}, \ldots I_{n}
$$

represent $n$ successive readings of the same signal current $I$, taken at the times

$$
t, 2 t, \ldots, n t,
$$


and where $I(\nu t)$ is their expectation value, obtained from a least-squares fit of the measured data as a linear function of time.

The valves operating the two aperture shutters are actuated by the data acquisition and control system of the spectrophotometer in a manner such that twent $y$-seven readings,

$$
0, A+B, 0, A, 0, B, 0, A+B, 0, B, \ldots A, 0, A+B, 0
$$

are effected in 20-sec intervals. Here, 0 is a dark-current reading, and $A, B$, and $A+B$ are the readings obtained with either or both apertures open. These data are then processed as follows.

The dark currents on both sides of $A, B$, and $A+B$ are averaged and subtracted from these readings, yielding a sequence of thirteen adjusted signal currents.

$$
I(A+B), I(A), I(B), I(A+B), I(B), \ldots I(A), I(A+B) .
$$

The averages $\overline{I(A)}, \overline{I(B)}$, and $\overline{I(A+B)}$ are then used to compute

$$
\left.\sigma^{\prime}=\overline{I(A+B)} / \overline{[I(A)}+\overline{I(B)}\right]-1 \text {, }
$$

as defined in Eq. 5 above.

The quantities,

$$
Y=I(A) / \overline{I(A)}, I(B) / \overline{I(B)} \text {, and } I(A+B) / \overline{I(A+B)}
$$

are fitted to a straight line, $Y(t)$, respective to the times $t$ at which the data were taken, so that $\overline{I(A)} Y(t), \overline{I(B)} Y(t)$, and $\overline{I(A+B) Y(t)}$ represent the expectation values of the data sequence in Eq. (16b). Hence, the standard deviations $d I(A), d I(B)$, and $d I(A+B)$ are computed using Eq. (15a). Finally the propagation-of-error formula below is used to calculate the estimated standard deviation do of the measured value of $\sigma^{\prime}$.

The standard deviation $d \sigma^{\prime}$ of a single measurement of the nonlinearity term $\sigma^{\prime}$ is given by

$$
\begin{gathered}
{\left[d \sigma^{\prime}(A, B)\right]^{2}=\left[\frac{\partial \sigma^{\prime}}{\partial I(A)} d I(A)\right]^{2}+\left[\frac{\partial \sigma^{\prime}}{\partial I(B)} d I(B)\right]^{2}+\left[\frac{\partial \sigma^{\prime}}{\partial I(A+B)} d I(A+B)\right]^{2}} \\
=\frac{1}{[I(A)+I(B)]^{2}}\left\{\left(1+\sigma^{\prime}\right)^{2}\left[d I(A)^{2}+d I(B)^{2}\right]+d I(A+B)^{2}\right\}
\end{gathered}
$$


where dI is the photometric error of the spectrophotometer defined by Eq. (15a).

E. Uncertainties

1. Instrumental Bias

Because of the special design of the RTS, the combined systematic error introduced by the spectrophotometer itself into measurements of the true regular transmittance defined in Section II.A has been minimized. The individual components of this error are discussed in Reference [1] and are here summarized as follows.

Beam-displacement and defocusing effects: These are undetectable due to the parallel-beam geometry of the instrument and the use of an averaging sphere in front of the photomultiplier tube.

Interreflections between monochromator exit aperture and sample: This effect is undetectable when a clear glass plate is used as the sample, a case in which the error is prominent in other instruments.

Obliquity errors: Path length and Fresnel reflectance effects due to the residual non-parallelism of the beam and/or imperfect sample alignment were calculated and also found negligible.

Polarization effects: These are accounted for by performing all measurements in linearly polarized light.

Detector errors: All measurements are corrected for dark current and linear drift of the photomultiplier signal. The non-linear component of the drift is treated as noise and is included in the random error quoted for each measurement. The uncertainty in the non-linearity correction (3o) applied to all measurements is of the order of $10^{-5}$ transmittance units.

Wavelength bias: The est imated uncertainty $(3 \sigma)$ of the wavelength correction applied to all measurements is $0.04 \mathrm{~nm}$. The corresponding transmittance uncertainty is sample-dependent and is given by

$$
\Delta T=0.04 \mathrm{dT} / \mathrm{d} \lambda \text {. }
$$

This error is smaller than $2 \times 10^{-5}$ transmittance units for commonly measured spectrally neutral filters for which the transmittance does not vary by more than 0.005 over a $10-\mathrm{nm}$ interval. When samples with pronounced spectral 
features are measured, the error calculated from the above formula will be included in the random error quoted for the measurement.

Stray light: The error due to stray light also depends on the transmittance spectrum of the sample. From the measurements discussed in Section II.C.4 it may be estimated that it does not exceed $5 \times 10^{-5}$ transmittance units $(3 \sigma)$ in the worst case that all stray light is transmitted by the sample.

When all these errors are considered and added in quadratu'e, the result is less than $10^{-4}$ in the transmittance range 0.1 to 1.0 . When lower transmittances are measured by the step-down technique described in Appendix $A$, the instrumental bias decreases in accordance with the equations given in that appendix. Hence, the over-all instrumental uncertainty shown by the upper curve in Figure 6 has been assigned to the RTS.

\section{Random Errors}

Uncertainties due to light source fluctuations, electronic noise, and shot noise are the main sources of random variations. The uncertainties due to these fluctuations may be reduced by repeated measurements. Normally a run consisting of four measurements is satisfactory.

Measurements of a large number of filters (approximately 20) with different transmittances made it possible to plot the dependence of the standard deviation on transmittance. This graph is presented as the lower curve in Figure 6 , and shows one standard deviation based on four measurements, each, of transmittances between 0.0001 and 0.92 .

3. Sample-Induced Uncertainties

Sample properties such as non-uniformity, thermochromism, lack of parallelism of surfaces, and scattering must be considered separately in each case.

Non-uniformity can be one of the major sources of error. Even the best available filters are non-uniform. The effect on a particular application will be determined by the spot size on the filter used and the requirements for displacement due to alignment or use differences. Some examples of non-uniformity are given in Appendix $A$ and reference [6]. Some typical 


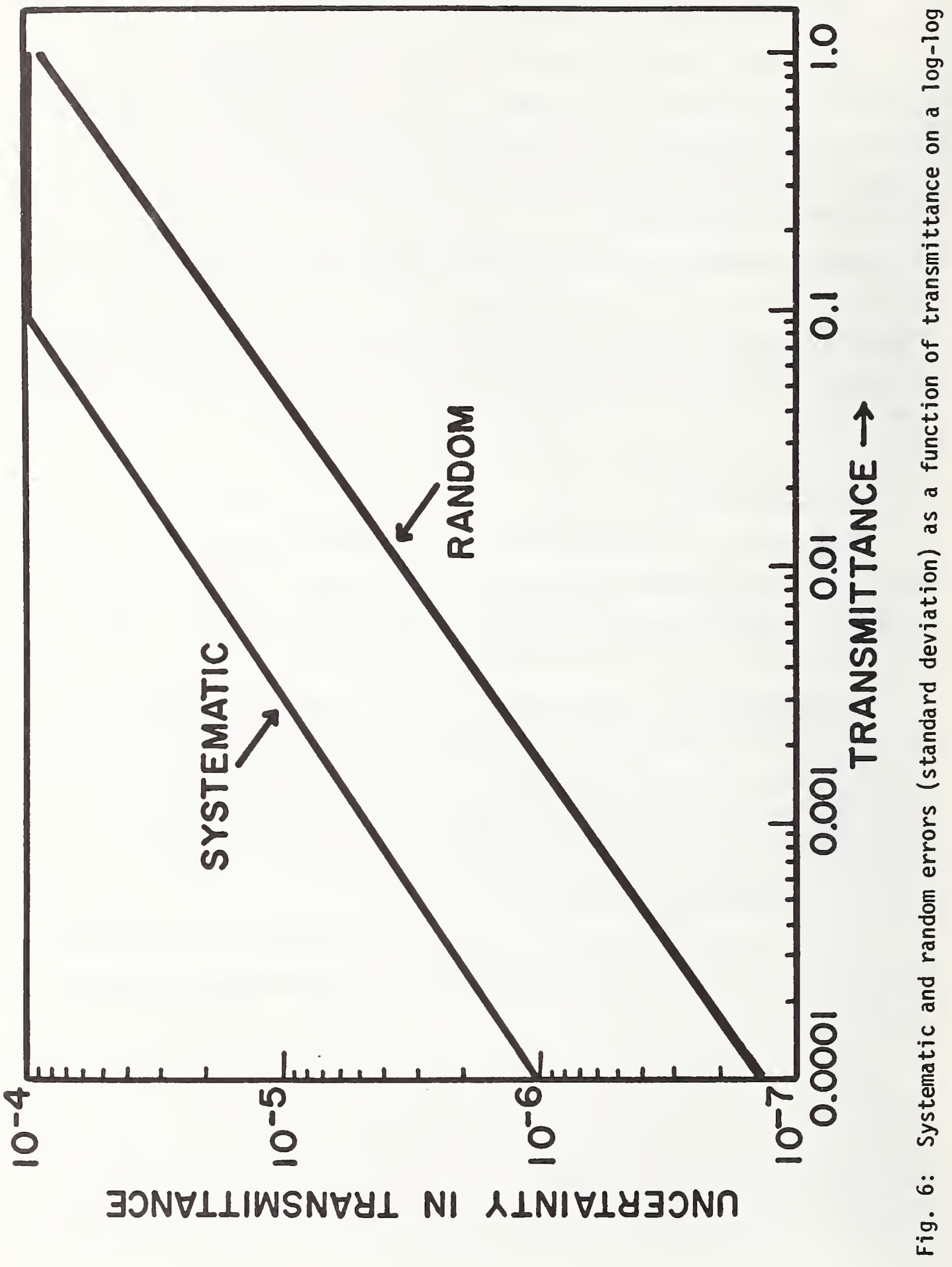


values of non-uniformity are 0.1 to 0.5 percent of the transmittance (equivalent to a $3 \sigma$ systematic uncertainty).

Thermochromism becomes a problem for the measurement of colored filters. When such filters are measured, it is necessary to monitor the temperature carefully, or even to determine temperature coefficients for transmittance. Thermochroism is not normally a problem for neutral filters.

Surfaces for high quality filters are quite parallel. Scattering, both surface and volume, is negligible for quality filters. This is verified by experiment. Not only is the scattering small but the RTS solid angle of acceptance (approximately 0.0027 steradian) is sufficiently small to reject a diffuse component.

\section{Total Uncertainty}

Table 6 lists the component uncertainties and the over-all uncertainty for high quality neutral filters. The instrumental systematic error $(3 \sigma$

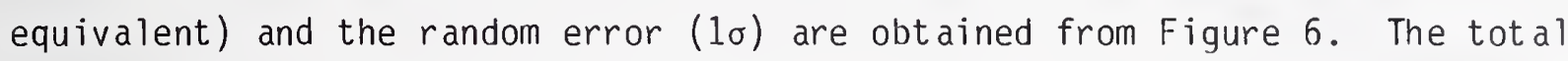
instrument uncertainty is obtained by adding in quadrature (square root of the sum of squares) the instrumental systematic error and three times the random error. The sample induced uncertainties (3o) listed are estimated as $0.1 \%$ of the transmittance. The over all uncertainty is obtained by adding in quadrature the instrument uncertainty and the sample induced uncertainty. It is seen that for high transmittances, sample induced errors predominate; and at low transmittances instrumental uncertainties become important.

F. Report of Test

A typical report (see Appendix A) contains all of the important parameters for a given test and a description of the measurements. The results are presented in tables with associated uncertainties.

G. Safety.

A 5mW helium-neon laser and ultraviolet-emitting low-pressure-discharge 1 amps are used in the RTS laboratory. Appropriate warning signs are displayed at the entrance to the laboratory when these sources are in use. Safety glasses are worn when the ultraviolet lamps are used. A large light-tight enclosure to the instrument must be raised to allow access when major changes are made in the RTS. Care must be $t$ aken when raising and 
Table 6

Typical Over-all Uncertainties for NBS Reference Spectrophotometer

\begin{tabular}{|c|c|c|c|}
\hline \multirow[b]{2}{*}{ Source of Error } & \multicolumn{3}{|c|}{ Transmittance } \\
\hline & $T=0.01$ & $T=0.1$ & $T=1.0$ \\
\hline A. Instrumental Bias (Systematic) & $2.0 \times 10^{-5}$ & $1.0 \times 10^{-4}$ & $1.0 \times 10^{-4}$ \\
\hline $\begin{array}{l}\text { B. Random Error } \\
(3 \times \text { St andard Deviation })\end{array}$ & $1.0 \times 10^{-5}$ & $0.6 \times 10^{-4}$ & $2.7 \times 10^{-4}$ \\
\hline $\begin{array}{l}\text { Total Measurement Uncertainty } \\
\qquad\left(A^{2}+B^{2}\right)^{1 / 2}\end{array}$ & $2.2 \times 10^{-5}$ & $1.2 \times 10^{-4}$ & $2.9 \times 10^{-4}$ \\
\hline C.Sample Induced Errors & $1.0 \times 10^{-5}$ & $1.0 \times 10^{-4}$ & $1.0 \times 10^{-3}$ \\
\hline $\begin{array}{l}\text { Overall Uncertainty } \\
\qquad\left(A^{2}+B^{2}+C^{2}\right)^{1 / 2}\end{array}$ & $2.4 \times 10^{-5}$ & $1.5 \times 10^{-4}$ & $1.0 \times 10^{-3}$ \\
\hline
\end{tabular}


lowering the enclosure to ensure that turning the lift mechanism results in movement of the enclosure. The usual precautions are observed when using chemicals for stray light tests. Other precautions taken are the usual ones when working with electrical laboratory equipment.

III. Transfer Spectrophotometer for Regular Transmittance

A. Description of the Instrument [18]

1. Wavelength Range

The overall wavelength range of the instrument is 185 to $3150 \mathrm{~nm}$. The monochromator uses two gratings, one covering the UV-VIS (185 to $900 \mathrm{~nm}$ ), and the other covering the NIR (700 to $3150 \mathrm{~nm}$ ). A deuterium lamp is used as the UV source below $340 \mathrm{~nm}$ and a tungsten-halogen lamp is used for the 340 to 3150 range. The wavelength scan $r$ ate can be selected between 0.01 and 10 $\mathrm{nm} / \mathrm{s}$, and repeated scans of selected wavelength ranges $c$ an be made aut omat ically.

\section{Bandwidth Range}

The spectral bandwidth can be set to any fixed value between 0.1 and 3.6 $\mathrm{nm}$ for the wavelength range 185 to $900 \mathrm{~nm}$ when using the photomultiplier detector. The bandwidth, in the near infrared, may range from less than $1 \mathrm{~nm}$ to a maximum of $14.3 \mathrm{~nm}$, depending on the available signal. The signal gain is increased or decreased to narrow or widen the bandwidth, respectively, in the near infrared.

\section{Photometric Range}

The photometric range in the transmittance mode is ordinarily 0 to $100 \%$. The chart recorder can be programmed to display zero to $200 \%$ (in case the sample fluoresces). A zero suppress allows expansion of the upper portion of the scale.

The photometric range in the transmission density mode* is 0 to 4.5 . The instrument is programmed to give a "data out of range" message on the

*The transmission density is defined to be the logarithm to the base ten of the reciprocal transmittance. 
parameter display monitor screen, when the density exceeds 4.5. This same message is displayed in the transmittance mode when the transmittance is less than $0.01 \%$. In order to measure higher densities than 4.5, special photoetched nickel screens are inserted into the reference beam. This technique extends the density range to approximately 6 . However, the density scale in the NIR is limited to a range of 0 to 3 due to the noise of the lead sulfide detector.

\section{Temper ature Control}

The sample compartment is thermally insulated and equipped with water circulating tubing for controlling the sample temperature to $\pm 0.2^{\circ} \mathrm{C}$ between approximately $15^{\circ} \mathrm{C}$ and $40^{\circ} \mathrm{C}$. The temperature of a sample is monitored by means of a thermocouple probe which measures the ambient temperature inside the sample compartment. The temperature is displayed on the parameter monitor or recorded as a function of time during a spectral scan.

5. Data Acquisition and Automation

Spectral transmittance data can be recorded with the chart recorder, or printed in digital form by a thermal printer.

The spectrophotometer can be operated manually, or it can be controlled by the external computer. This computer is used to store spectral data on floppy disks, and to perform data reductions, such as correcting for baseline drift or converting absorbance to transmittance and vice-versa. There are special programs for computing colorimetric terms, performing spectral averaging, and plotting data.

B. Instrument Calibration

1. Wave length

Calibration of the instrument wavelength scale is performed by comparing the measured peaks of emission lines and absorption bands with reference data [19] for the wavelengths of these peaks. The emission lines and absorption bands used are listed in Table 7.

To produce the $\mathrm{Hg}$, $\mathrm{Ne}$, Xe, and $\mathrm{Kr}$ lines listed in Table 7, pen-ray lamps are placed in the lamp compartment of the spectrophotometer. The absorption bands are produced by $1 \mathrm{~cm}$ path length cuvettes placed in the sample comp artment. 
Emission Lines and Absorption Bands Used to Calibrate the Transfer Spectrophotometer Wavelength Scale.

\section{Emission Lines:}

$\mathrm{Hg}: 253.65 \mathrm{~nm}, 334.15 \mathrm{~nm}, 435.83 \mathrm{~nm}, 1014 \mathrm{~nm}, 1529 \mathrm{~nm}$.

$\mathrm{D}_{2}: 486.0 \mathrm{~nm}, 656.10 \mathrm{~nm}, 1312.2 \mathrm{~nm}, 1968.3 \mathrm{~nm}, 2624.4 \mathrm{~nm}$.

Note: The last 3 wavelengths for $D_{2}$ are the 2 nd, $3 r d$, and 4 th order lines of the $656.1 \mathrm{~nm}$ line and are observed with the near infrared grating.

Ne: $703.24 \mathrm{~nm}$.

Xe: $881.94 \mathrm{~nm}, 979.97 \mathrm{~nm}$.

$\mathrm{Kr}: 1816.73 \mathrm{~nm}$.

\section{Absorption bands of Materials;}

1,2,4-trichlorobenzene $(0.5 \mathrm{~mm}): 2152.6 \mathrm{~nm}$.

Holmium oxide (SRM 2034): $241.0 \mathrm{~nm}, 249.8 \mathrm{~nm}, 278.1 \mathrm{~nm}, 287.0 \mathrm{~nm}$, $333.5 \mathrm{~nm}, 345.5 \mathrm{~nm}, 361.4 \mathrm{~nm}, 385.4 \mathrm{~nm}$, $416.1 \mathrm{~nm}, 451.3 \mathrm{~nm}, 467.8 \mathrm{~nm}, 485.3 \mathrm{~nm}$, $536.5 \mathrm{~nm}, 640.5 \mathrm{~nm}$.

Rare-Earth 0xide (SRM 1920): $799.0 \mathrm{~nm}, 886.7 \mathrm{~nm}, 1132.4 \mathrm{~nm}, 1260.8 \mathrm{~nm}$, $1535.4 \mathrm{~nm}, 1682.2 \mathrm{~nm}, 1757.8 \mathrm{~nm}, 1847.0 \mathrm{~nm}$, $1932.5 \mathrm{~nm}, 1970.8 \mathrm{~nm}$. 
The $\mathrm{D}_{2}$ lines are produced by the deuterium lamp built into the spectrophotometer, and are used in automated day-to-day wavelength scale checks. In the UV and visible the $486.0 \mathrm{~nm}$ and $656.1 \mathrm{~nm} \mathrm{D}$ lines are used in the first grating order, and in the near IR they are used in the second, third, and fourth orders. The zeroth order is used as a further check.

The wavelength scale error is reduced to a minimum by adjusting the wavelength encoder mechanism. The following data are typical of the wavelength scale error:

\begin{tabular}{|c|c|c|}
\hline True Wavelength (nm) & Observed Wavelength ( $\mathrm{nm})$ & Error $(n m)$ \\
\hline 2624.4 & 2623.8 & -0.6 \\
\hline 1968.3 & 1967.9 & -0.4 \\
\hline 1312.2 & 1312.0 & -0.2 \\
\hline 656.10 & 656.12 & +0.02 \\
\hline 485.00 & 485.02 & +0.02 \\
\hline 0.00 & 0.13 & +0.13 \\
\hline
\end{tabular}

In calibration reports the wavelength uncertainty is generally stated to be $\pm 0.1 \mathrm{~nm}$ in the UV-VIS and $\pm 1.0 \mathrm{~nm}$ in the NIR. Since these values are upper bounds, the uncertainty is $3 \sigma$ in magnitude. Corrections are usually not applied but can be made in critical cases.

2. Linearity

The linearity of the photomultiplier tube of the spectrophotometer was checked with a set of transmittance standards $[5,6]$ following a comparison of their measured transmittances at $770 \mathrm{~nm}$ with the best values recently measured on the reference transmittance spectrophotometer. These measurements indicated that no linearity correction is necessary for measurements made with the PMT detector.

\begin{tabular}{|c|c|c|c|c|}
\hline Filter No. & Measured Value & Reference Value & Difference & $\%$ Difference \\
\hline $1-1$ & 0.9179 & 0.9185 & -0.0006 & -0.07 \\
\hline $1-2$ & .6641 & .6644 & -.0003 & -0.05 \\
\hline $1-3$ & .4788 & .4787 & +.0001 & +0.02 \\
\hline $1-4$ & .3286 & .3289 & -.0003 & -0.09 \\
\hline $1-5$ & .1669 & .1674 & -.0005 & -0.30 \\
\hline $1-6$ & .0497 & .0500 & -.0003 & -0.60 \\
\hline $1-7$ & .0115 & .01163 & -.0001 & -0.86 \\
\hline
\end{tabular}


The non-linearity of the lead sulfide detector was determined by comparing transmittance measurements at $770 \mathrm{~nm}$. The following differences were found, and are applied as non-linearity corrections for measurements made with the lead sulfide detector.

\begin{tabular}{|c|c|c|c|c|}
\hline Filter No. & Measured Value & Reference Value & Difference & $\%$ Difference \\
\hline $1-1$ & 0.9214 & 0.9185 & +0.0029 & +0.32 \\
\hline $1-2$ & .6663 & .6644 & +.0019 & +0.29 \\
\hline $1-3$ & .4800 & .4787 & +.0013 & +0.27 \\
\hline $1-4$ & .3300 & .3289 & +.0011 & +0.33 \\
\hline $1-5$ & .1669 & .1674 & -.0005 & -0.30 \\
\hline $1-6$ & .0484 & .0500 & -.0016 & -3.20 \\
\hline $1-7$ & .0097 & .01163 & -.0019 & -16.34 \\
\hline
\end{tabular}

3. Stray Radiation

The presence of stray radiation in the spectrophotometer sample beam was checked for spectral bandwidths (SBW) of $1 \mathrm{~nm}$ and $3.6 \mathrm{~nm}$ with ASTM Test Method E387 [17] using cutoff filters and pass-band filters. The results were as follows, indicating that the level of stray radiation in this spectrophotometer is not significant.

\begin{tabular}{clll} 
Wavelength $(\mathrm{nm})$ & $\begin{array}{l}\text { Filter or } \\
\text { Solution }\end{array}$ & $\frac{1 \mathrm{~nm} \mathrm{SBW}}{3.6 \mathrm{~nm} \mathrm{SBW}}$ \\
\cline { 1 - 3 } 200 & $\mathrm{KCL}$ & $3.38 \times 10^{-6}$ & $5.75 \times 10^{-7}$ \\
215 & $\mathrm{NaBr}$ & $3.54 \times 10^{-7}$ & $1.90 \times 10^{-5}$ \\
245 & $\mathrm{NaI}$ & $4.36 \times 10^{-7}$ & $1.17 \times 10^{-6}$ \\
318 & Acetone & $5.01 \times 10^{-7}$ & $3.89 \times 10^{-6}$ \\
380 & $\mathrm{NaNO}_{2}$ & $2.04 \times 10^{-6}$ & $1.47 \times 10^{-5}$ \\
512 & Red \#222 & $2.39 \times 10^{-6}$ & $2.88 \times 10^{-6}$ \\
568 & Red \#3059 & $8.91 \times 10^{-7}$ & \\
660 & Methylene Blue & $3.89 \times 10^{-6}$ & \\
671 & Methylene Blue & & $4.16 \times 10^{-6}$ \\
688 & Red \#3002 & & $5.12 \times 10^{-7}$
\end{tabular}




\section{St ability}

The wavelength scale error will remain constant after a warm-up time of approximately one hour, if the temperature of the instrument remains stable. The photometric scale drift is checked by observing changes in the baseline $(100 \%)$ calibration. A baseline drift of $0.1 \%$ in one hour is common. If measurements require several hours, the baseline is recorded at the beginning and ending of the run to determine the drift. The baseline is also measured repeatedly when making multiple.scans. Corrections for baseline drift are part of the standard data reduction procedures.

\section{Operational Procedures}

1. Instrument Parameters

Instrument parameters (wavelength range, bandwidth, scan speed, data interval, and choice of transmittance or absorbance scale) are set after a 30 minute warm-up period. The wavelength scale is checked at this time by running the built-in test with the deuterium emission lines. The baseline is set before any measurements are recorded. In setting the baseline, the instrument scans the spectral region to be measured and stores the data in a memory that compares the sample and reference beam intensities. If these two signals are the same, the baseline correction is zero. If they are not the same, a record of the difference is kept in the memory. These differences are used to correct later measurements for baseline errors. As long as subsequent measurements are made under the same instrument parameters, the recorded baseline will be used. If the operator changes the gain, bandpass, or wavelength range, the instrument will display a warning message on the monitor so that a new baseline will be set for the new conditions.

The use of this baseline correction technique does not eliminate the need for recording a $100 \%$ calibration curve at the beginning and end of a set of measurements to determine baseline drift. A zero transmittance curve does not have to be recorded because the instrument does not register negative transmittances or transmittances less than $0.01 \%$ (approximately optical density 4). In the absorbance mode, optical densities greater than 4.5 can be recorded by special techniques. 
2. Measurement Sequence for Transmittance or Absorbance

The measurements are recorded in the sequence: 100\%, test sample, $100 \%$. In the absorbance mode, the sequence is the same except that the $100 \%$ becomes the zero absorbance calibration.

\section{Data Reduction}

The data for the test sample are usually divided by the data for the $100 \%$ calibration. If the $100 \%$ calibration drifts between the beginning and ending $100 \%$ measurements, the average $100 \%$ is used in adjusting the sample data. If the drift exceeds $0.3 \%$ in the $100 \%$ calibration, the measurements are rejected until the condition is corrected. In the case of absorbance measurements, the zero absorbance calibration is subtracted from the sample data.

\section{Uncertainties}

The uncertainty (3o) for regular transmittance is generally 0.003 in the ultraviolet-visible range and 0.008 in the near infrared range. The photometric scale uncertainties arise from factors such as non-linearity of the photometric scale, stray radiation, random noise, stability of the

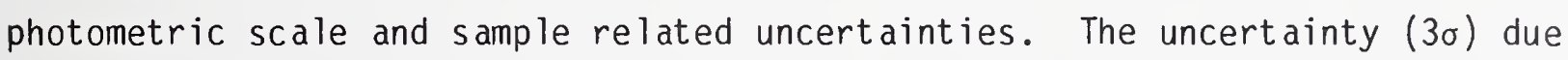
to non-linearity is less than 0.001 for transmittance greater than 0.3 . The error due to stray radiation is less than 0.00002 . The uncertainty due to random noise varies with a number of instrumental operational parameters. Noise (3o) may be as small as $0.02 \%$ or as much as $2 \%$ depending on such parameters as spectral bandwidth, wavelength range, and available reference signal. A typical noise level is 0.0025 . When random noise is relatively high, the effects of noise on the measurements is reduced by averaging ten measurements at each wavelength. As stated in Sec. III.B.1, the wavelength scale uncertainty $(3 \sigma)$ is $\pm 0.1 \mathrm{~nm}$ in the ultraviolet and visible spectral range and $\pm 1.0 \mathrm{~nm}$ in the near infrared. The influence of wavelength error on the over-all uncertainty depends on the rate of change in transmittance versus change in wavelength. A typical uncertainty (3o) in transmittance due to wavelength error is 0.0005 for a neutral sample in the visible spectral range. In measuring samples for which the transmittance changes rapidly with wavelength, a correction is made for the wavelength scale error. The stability (3o) of the photometric scale over a period of three hours is better than 0.003 . Since the average of the first and last $100 \%$ curve is 
used, the uncertainty due to drift will not exceed 0.0015. The drift is linear and can be minimized by recording the 100\% calibration at shorter time intervals and correcting for changes in this calibration. The estimated typical uncertainties (3o) are summarized in Table 8 for transmittances in the range 1.0 to 0.10 for the visble. The relative uncertainty increases for lower transmittance. For transmittances between 0.10 and 0.001 the uncertainty changes from approximately 0.0030 to 0.00027 for a typical case. The uncertainty for a 0.001 transmittance filter can be reduced to 0.00005 if a linearity correction is applied. The non-linearity of the photometric scale has not been assessed for transmittances less than 0.001 .

\section{Reports of Test}

The "Report of Test" (see Appendix B) is an important documentation of services performed. The report includes such information as: (1) The purpose of the test; (2) a description of the test samples; (3) a description of the instrumentation, measurement parameters, and procedures; (4) details of the data reduction and estimates of the uncertainties; (5) comments and references; and (6) tables of data and calculated results.

\section{E. Safety}

The same safety precautions are followed with the transfer instrument as those described above for the reference instrument. 
Table 8

Summary of Estimated Uncertainties in Percent of Spectral

Transmittance Values for NBS Transfer Spectrophotometer [A

Representative Analysis (Three Sigma) in the Visible Region for

Transmittances in the Range .1-1.0]

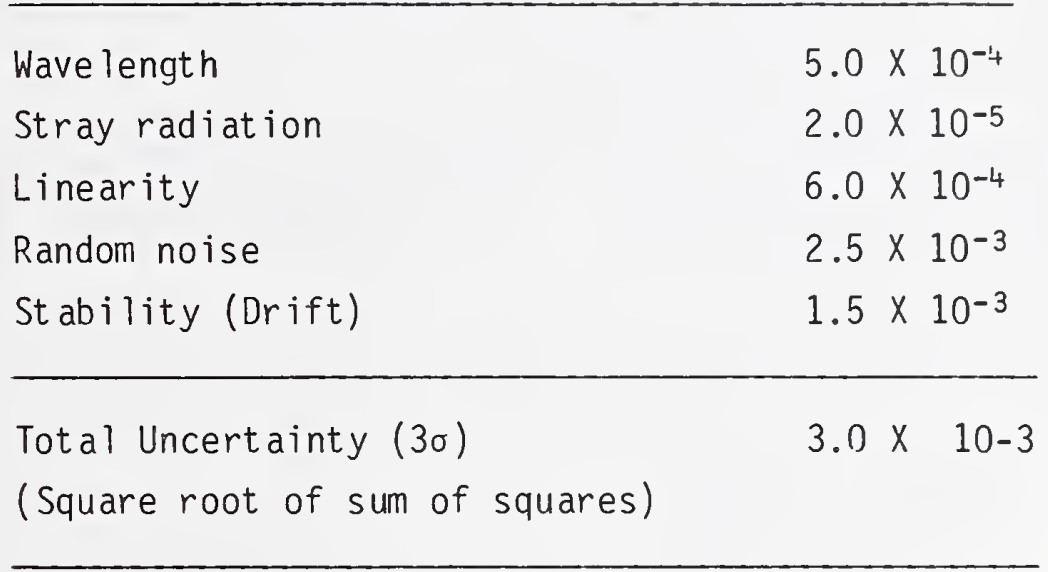




\section{REFERENCES}

1. Mielenz, K. D., Eckerle, K. L., Madden, R. P., and Reader, J., "New Reference Spectrophotometer", App 1. Opt. 12 (7), 1630 (July 1973).

2. Mielenz, K. D., and Eckerle, K. L., "Design, Construction, and Testing of a New High Accuracy Spectrophotometer", NBS Technical Note 729 (June 1972).

3. Eckerle, K. L., "Modification of an NBS Reference Spectrophotometer", NBS Technical Note 913 (July 1976).

4. Eckerle, K. L., Weidner, V. R., Hsia, J. J., and Chao, Z. W., "Extension of a Reference Spectrophotometer into the Near Infrared", NBS Technical Note 1175 (April 1983).

5. Eckerle, K. L., Weidner, V. R., Hsia, J. J., and Kafadar, K., "Measurement Assurance Program Transmittance Standards for Spectrophotometric Linearity Testing: Preparation and Calibration", J. of Res. of the NBS, 88, 1 (Jan.-Feb. 1983).

6. Eckerle, K. L., Hsia, J. J., and Weidner, V. R., "Transmittance MAP Service", NBS Special Publication 692, (March 1985).

7. Venable, W. H., and Eckerle, K. L., "Didymium Glass Filters for Calibrating the Wavelength Scale of Spectrophotometers - SRM 2009, 2010, 2013, and 2014", NBS Special Publication 260-66, (Oct. 1979).

8. Eckerle, K. L., Chang, S., and Hsia, J. J., "Calibration in 1976 and 1983 of Didymium Glass Filters Issued as NBS St andard Reference Materials", Color Res. and App 1., 10 (32) (Spring 1985).

9. Weidner, Victor R., Mavrodineanu, Radu, Mielenz, Klaus D., Velapoldi, Rance A., Eckerle, Kenneth L., and Adams, Bradley: Spectral Transmittance Characteristics of Holmium Oxide in Perchloric Acid Solution, J. Res. Nat. Bur. Stand. 90, 115 (March-April 1985).

10. Mielenz, K. D., "Physical Parameters in High-Accuracy Spectrophotometry", NBS Special Publication 378, (May 1973).. 
References (cont'd)

11. CIE Publication No. 17 (E-1.1) 1970, International Lighting Vocabulary, 3rd Edition, Bureau Central de la CIE, Paris (1970).

12. Eckerle, K. L., Venable, W. H. Jr., and Weidner, V. R., "Averaging Sphere for Ultraviolet, Visible, and Near Infrared Wavelengths: A Highly Effective Design", Appl. Opt. 15 (3) (March 1976).

13. Taylor, D. J., Rev. Sci. Inst., 40, 559 (1969).

14. Burke, R. W. and Mavrodineanu, R., "Accuracy in Analytical Spectrophotometry", NBS Special Publication 260-81, (April 1983).

15. Mavrodineanu, R. and Baldwin, J. R., "Glass Filters as A Standard Reference Material for Spectrophotometry - Selection, Preparation, Certification, Use, SRM 930", NBS Special Publication 260-51 (Nov. 1975).

16. Mielenz, K. D., and Ecker le, K. L., "Spectrophotometer Linearity Testing Using the Double Aperture Method", Appl. Opt. 11 (10) (0ct. 1972).

17. Estimating Stray Radiant Energy, 1970 Annual Book of ASTM Standards, Part 30, p. 1154 (1970).

18. Varian-Cary Model 2390 UV-VIS-NIR Spectrophotometer.

19. CRC Handbook of Chemistry and Physics, $63^{\text {rd }}$ Edition, CRC Press, Inc. (1982-1983) . 


\section{U.S. DEPARTMENT OF COMMERCE}

NATIONAL BUREAU OF STANDARDS

GAITHERSBURG, MARYLAND 20899

\section{REPORT OF TEST}

for

Spectral Transmittance

of

Four Neutral Filters

Submitted by

Laboratory $A$

(Authorization for this test was given in Purchase Order XYZ dated January 13, 1976.)

1. Purpose.

The purpose of this test is to determine the spectral transmittance of four glass filters at the wavelength $694.3 \mathrm{~nm}$.

2. Material.

The four neutral filters, which were supplied by Mr. Jones, are each approximately $51 \mathrm{~mm}$ square and had been cleaned and engraved by him. Each filter was engraved with the letters "NBS" in one corner along with the designation $1.00,2.00,3.0$ and $4.0 \mathrm{E}$ in another corner. The engraved numbers denote the approximate optical density of a particular filter.

3. iMeasurements.

Measurements of spectral transmittance of the filters were made using the reference spectrophotometer. A detailed description of the spectrophotometer has been published as NBS Technical Note 729, and a discussion of the systematic and random errors is included in the paper "New Reference Spectropinotometer" publisined in the July, 1973 issue of Applied Optics. Several developments have occurred since those publications appeared, including the installation of new source optics (mirrors), acquisition of a 600 groove/mm grating, and the use of an averaging sphere of a new type. The instrument has also been automated and is conirolled by a minicomputer. The latter development led to acquisition of data at variable time intervals and to an iterative procedure for eliminating the drift of the system.

The approximate spectral bandpass was $1.5 \mathrm{~nm}$, and the temperature was $25.0 \pm 0.5^{\circ} \mathrm{C}$. The filters were illuminated with collimated, polarized radiation normal to the specimen surface. Measurements were made 
with the electric vector of the incident radiation horizontal $\left(0^{\circ}\right)$ and vertical $\left(90^{\circ}\right)$. The solid angle subtended at the sample by the detection system was approximately 0.0027 steradians. The illuminated area on the samples (centered unless otherwise specified) was a $16 \mathrm{~mm}$ diameter circle. The radiation was incident on the side of the filter on which the letters "NBS" were engraved, and these letters were in the upper left corner of the filter when viewed from the direction of incidence.

For specimens with transmittances between 0.1 and 1.0 , measurements are usually made relative to air. However, when the transmittance of the test filter is less than 0.10, increased accuracy can be obtained by using a step-down technique. The following page contains a description and an error analysis of this type of measurement. Therefore, the filter designated "1.00" was measured relative to air, filter "2.00" relative to filter "1.00", filter "3.0" relative to filter "2.00", and filter "4.0E" relative to filter "3.0". Since the filter designated "1.00" was measured relative to air, the final transmittance for all of the filters will be relative to air.

Transmittance measurements of the test filters were also made after shifting the filter in the illuminating beam by $4 \mathrm{~mm}$ in two directions normal to the beam. The resulting data indicate the magnitude of errors that would be caused by misalignment and nonuniformity of the filters.

The Tables contain the transmittance, instrumental systematic error, and standard deviation based on four measurements. The errors due to properties of the filters such as non-uniformity, and those due to variations in the filter environment, such as temperature changes, can cause further uncertainty in a particular measurment. To obtain the total uncertainty to the $99.7 \%$ confidence level, the instrumental uncertainty, three times the standard deviation, and other filter dependent uncertainties should be added in quadrature.

Table 1 contains transmittance data for the filters at $694.30 \mathrm{~nm}$ along with the estimated systematic errors and standard errors based on four measurements. The uniformity of the filters is indicated in Table 2.

Prepared by:

Approved by:

NBS Test No.: 534/ABC

Date: January 26, 1976 
Error analysis for measurements of transmittance using the reference spectrophotometer and the "step-down" technique.

The transmittance $T$ of a filter relative to air can be calculated from the expression

$$
T=T_{A} T_{B}
$$

where $T_{A}$ is the transmittance of a reference filter, and $T_{B}$ is the transmittance of the filter being tested relative to the transmittance of the reference filter.

An error analysis shows that the error of measurement by this procedure is smaller than the error that results when the test filter is measured directly relative to air.

The inaccuracy in the value of $T$ due to systematic errors will be called $\Delta \mathrm{T}_{\mathrm{S}}$ and is given by

$$
\Delta T_{S}=T_{A} \Delta T_{B}+T_{B} \Delta T_{A}
$$

where $\Delta T_{A}$ is the inaccuracy of $T_{A}$ and $\Delta T_{B}$ is the inaccuracy of $T_{B}$.

The standard error in $T$ due to random fluctuation will be called $\Delta T_{R}$ and is given by

$$
\Delta T_{R}=T\left[\left(\frac{\Delta T_{A}^{\prime}}{T_{A}}\right)^{2}+\left(\frac{\Delta T_{B}^{\prime}}{T_{B}}\right)^{2}\right]^{1 / 2}
$$

where $\Delta T^{\prime}$ is the standard error for the transmittance measurement of filter $A^{A}\left(T_{A}\right)$ and $\Delta T_{B}^{\prime}$ is the standard error for the transmittance measurement of filter $B$ relative to filter $A\left(T_{B}\right)$. 


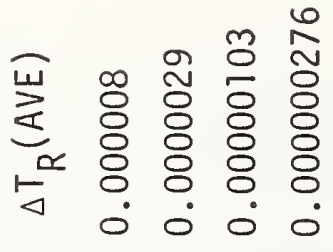

$$
\begin{aligned}
& \text { 山 } \\
& \text { 岁 } 3 \text { \& } \\
& \text { ฯ }
\end{aligned}
$$

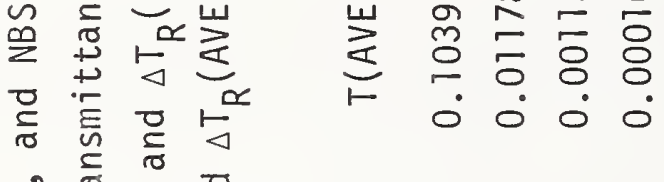

$$
\begin{aligned}
& \text { 仓. }
\end{aligned}
$$

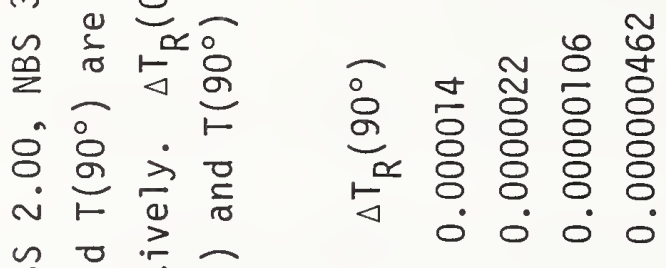

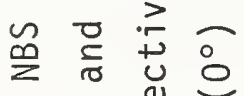

$$
\begin{aligned}
& \text { ᄋ }
\end{aligned}
$$

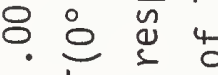

$$
\begin{aligned}
& \text { थ }
\end{aligned}
$$

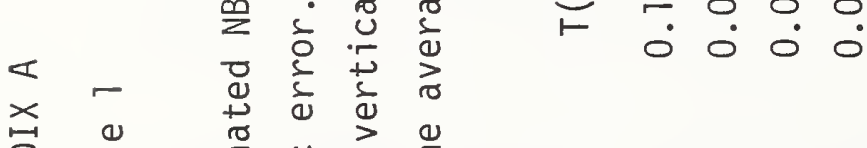

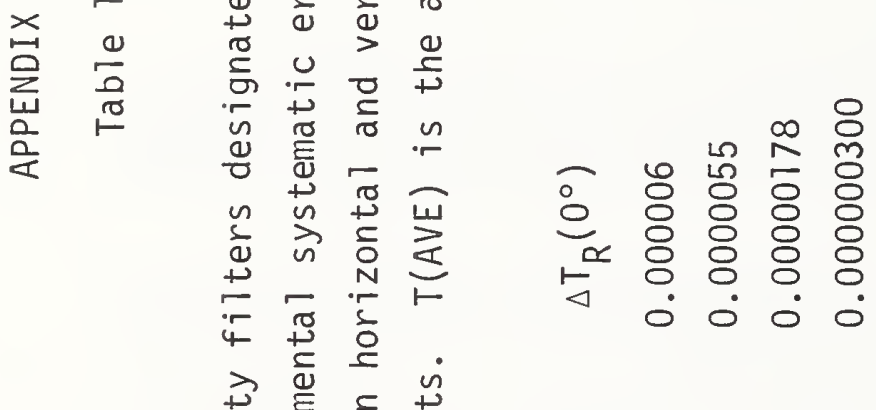

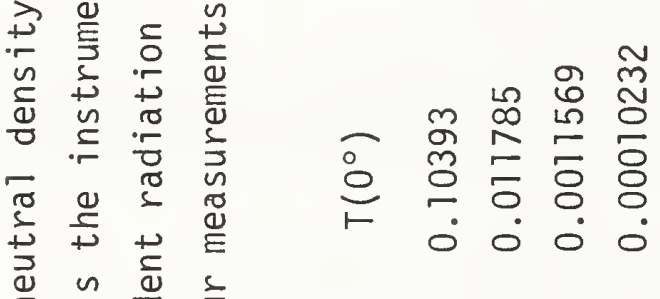

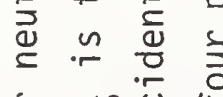

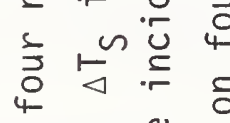

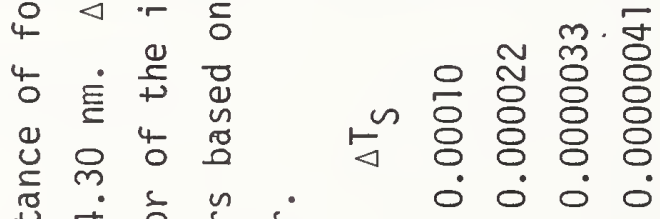

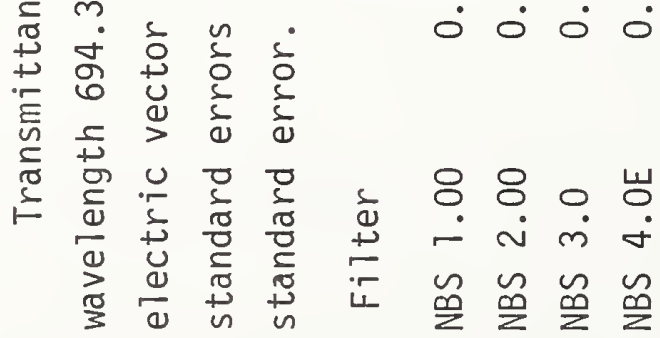




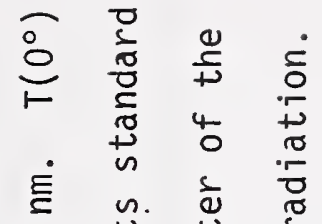

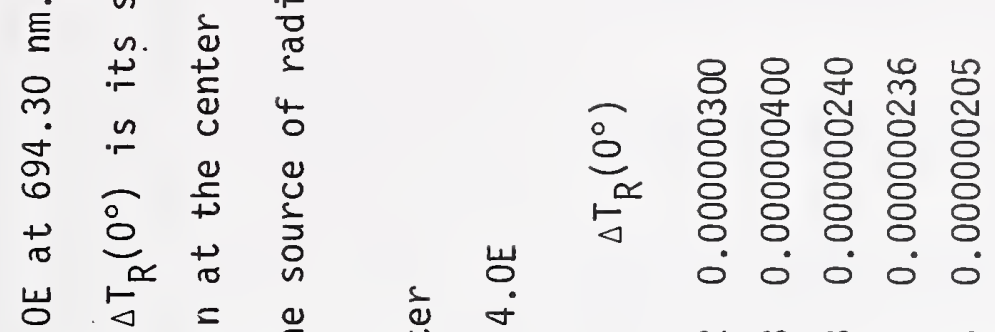

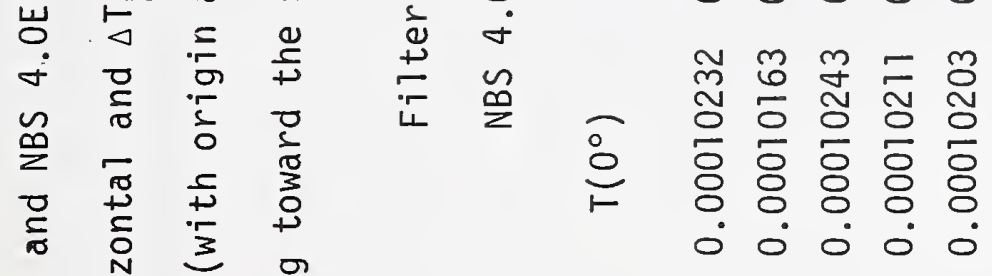

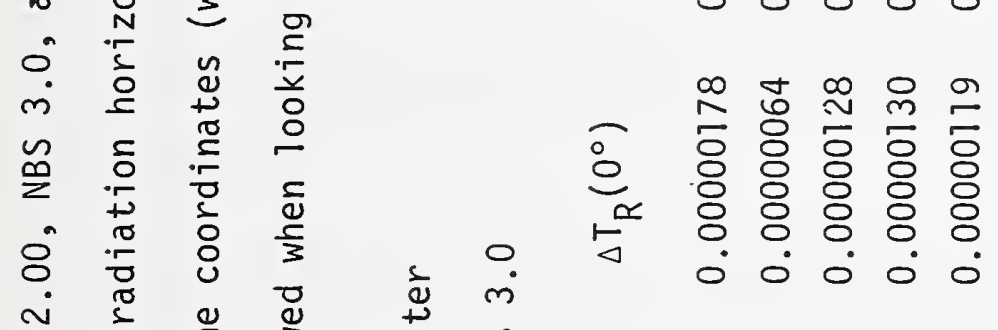

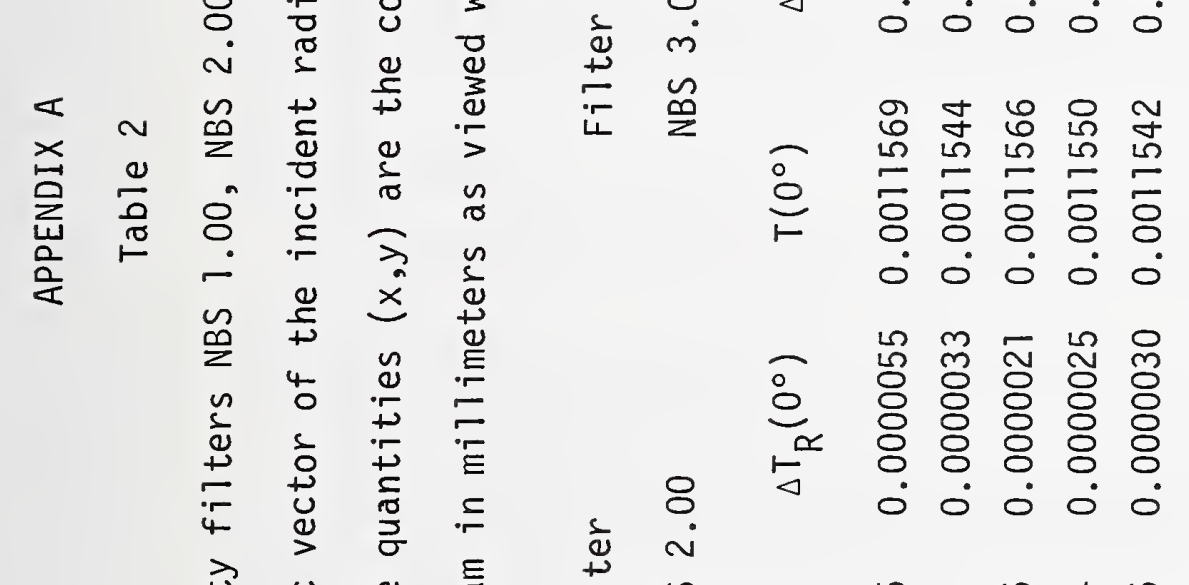

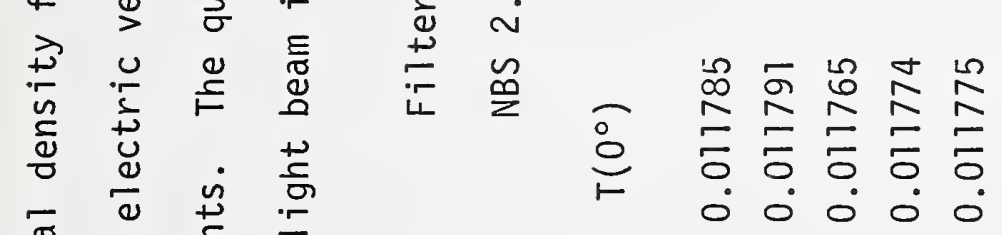

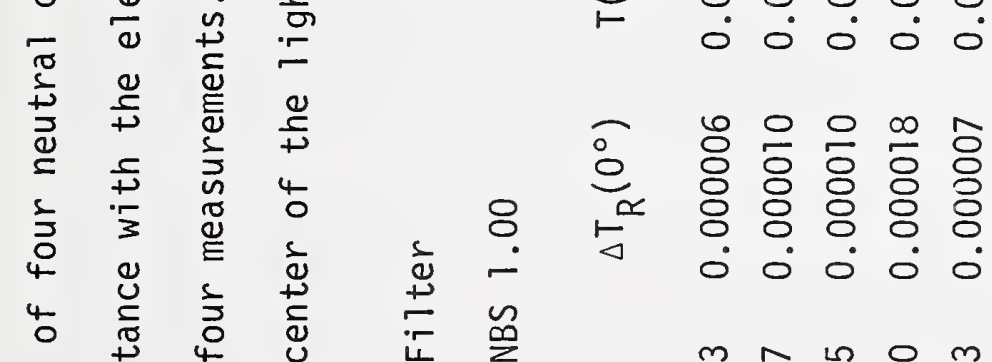

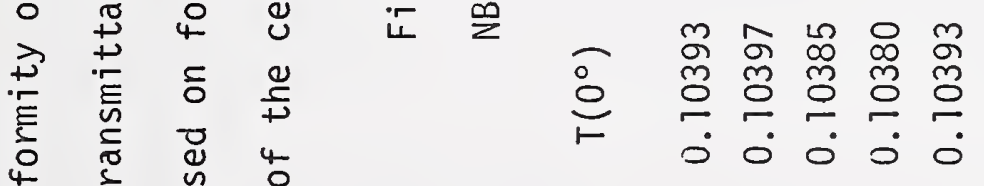

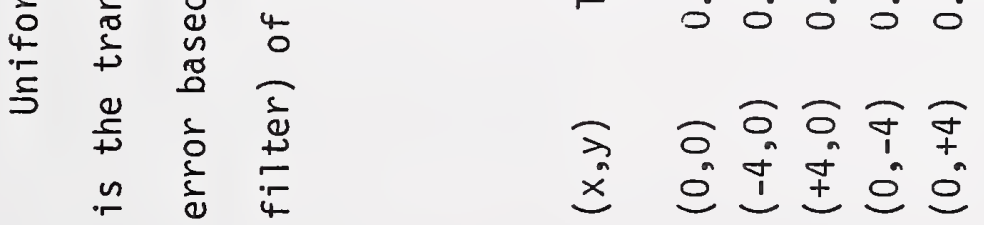


U.S. DEPARTMENT OF COMMERCE

NATIONAL BUREAU OF STANDARDS

GAITHERSBURG. MARYLAND 20899

\title{
REPORT OF TEST
}

\author{
for \\ Spectra] Transmittance \\ of
}

One Tiffen Neutral Density Filter

Submitted by:

Laboratory B

(Reference Purchase order No. ABC dated January 6, 1986.)

1. Purpose

The purpose of this test is to measure the spectral transmittance of one Tiffen neutral density filter over the spectral range 380 to $770 \mathrm{~nm}$.

\section{Materials}

The Tiffen neutral density filter is identified by the designation \#511.

\section{Measurements of Spectral Transmittance}

Measurements of spectral transmittance of the Tiffen neutral density filter were made by means of a Varian-Cary Model 2390 recording spectrophotometer over the spectral range 380 to $770 \mathrm{~nm}$ with a spectral band pass of $7-n m$.

The filter was placed in a sample beam at the focal plane where an image of the exit slit of the monochromator forms. The image is approximately $8 \mathrm{~mm}$ by $2 \mathrm{~mm}$ at the center of the filter. The sample beam converges at the focal plane with a semi-angle of approximately 1 degree.

\section{Data Reduction and Results}

The spectral data of the test filters and zero density calibration were recorded on an optical density (-log T) scale at 10-nm intervals.

NBS Test No.: 534/XYZ-86

Date: January 16,1986 
The data for the test filter were corrected for small variations in the zero calibration and converted to equivalent values of spectral transmittance.

The results of the data reduction are listed in table 1. 5. Uncertainties

The spectral transmittances listed in the table are believed to be uncertain by no more than \pm 0.3 percent (three sigma). These uncertainties are based on knowledge of the linearity of the Cary Model 2390 photometric scale as determined through extensive measurements of a set of master neutral density filters that are periodically calibrated on the NBS Reference Spectrophotometer for high accuracy transmittance measurements.

Prepared by:

Approved by:

NBS Test No.: 534/XYZ-86

Date: January 16,1986 
APPENDIX B

\section{TABLE 1}

TIFFEN N.D. FILTER $60 \%$ \#511

TRANSMITTANCE

WAVELENGTH (NM)

380

390

400

410

420

430

440

450

460

470

480

490

500

510

520

530

540

550

560

570

580

590

600

610

620

630

640

650

660

670

680

690

700

710

720

730

740

750

760

770

\section{(\%)}

59.95

61.82

62.70

62.59

62.42

62.33

62.22

62.37

62.56

62.57

62.57

62.56

62.60

62.60

62.56

62.52

62.47

62.42

62.33

62.22

62.04

61.97

61.80

61.66

61.48

61.31

61.12

60.95

60.72

60.51

60.33

60.12

59.88

59.68

59.44

59.21

58.97

58.71

58.49

58.25

NBS TEST No.: 534/XYZ-86

Date: January 16, 1986

B-3 


\begin{tabular}{|c|c|c|c|}
\hline U.S. DEPT. OF COMM. & 1. PUBLICATION OR & 2. Performing Organ. Report No. & 3. Publication Date \\
BIBLIOGRAPHIC DATA & REPORT NO. & & Ju1y 1987 \\
\hline SHEET (See instructions) & NBS/SP-250/6 & & \\
\hline
\end{tabular}

4. TITLE AND SUBTITLE

NBS Measurement Services: Regular Spectral Transmittance

5. AUTHOR(S)

Kenneth L. Eckerle, Jack J. Hsia, Klaus D. Mielenz, and Victor R. Weidner

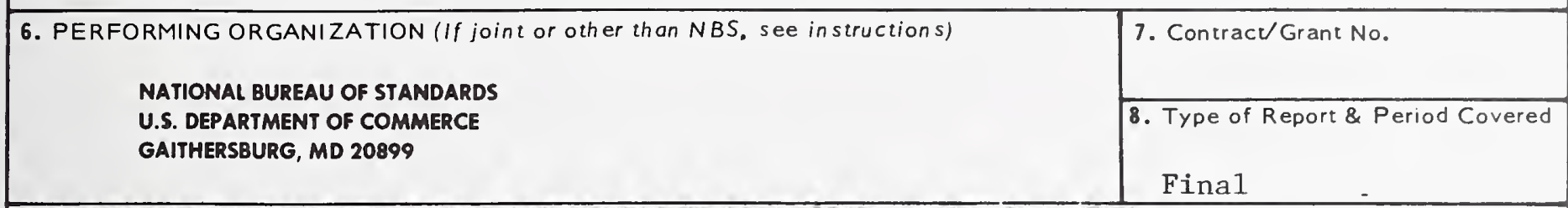

9. SPOHSORING ORGAAHZATION NAME AND COMPLETE ADCRESS (Street, CItY. Stute, ZIP)

Same as item 非6 above.

10. SUPPLEMENTARY NOTES

Library of Congress Catalog Card Number: 87-619840

[ Document describes a computer program; SF-185, FIPS Software Summary, is attached.

11. ABSTRACT (A 200-word or less factual summary of most significant information. If document includes a significant bibliography or literature survey. mention it here)

This documentation describes measurement services, instrumentation, standards, and measurement techniques for regular spectral transmittance over the spectral range of 200 to $2500 \mathrm{~nm}$. It is divided into three parts. Part I describes the services and standards that are available and the guiding philosophy behind the efforts to provide a primary laboratory for spectral transmittance measurements. Part II describes the high accuracy reference spectrophotometer. Part III describes the high precision transfer spectrophotometer. The transfer instrument relies on master standards that are periodically calibrated using the reference spectrophotometer.

12. KEY WORDS (Six to twelve entries; alphabetical order; capitalize only proper names; and separate key words by semicolons) calibration; high accuracy; linearity; measurement service; stray light; transmittance; uncertainty; wavelength

13. AVAILABILITY

[x] Unlimited

$\square$ For Official Distribution. Do Not Release to NTIS

$\mathrm{X}$ Order From Superintendent of Documents, U.S. Government Printing Office, Washington, DC 20402.

14. NO. OF PRINTED PAGES

[] Order From National Technical Information Service (NTIS), Springfield, VA 22161 




\section{PUBLICATIONS IN THE SP 250 SERIES FROM THE CENTER FOR RADIATION RESEAR.CH}

SP 250-1 NBS Measurement Services:

Spectral Radiance Calibrations

J.H. Walker, R.D. Saunders, and A.T. Hattenburg

SP 250-2 NBS Measurement Services:

Far Ultraviolet Detector Standards

L.R. Canfield and $N$. Swanson

SP 250-3 NBS Measurement Services:

Radiometric St andards in the Vacuum Ultraviolet J.Z. Klose, J.M. Bridges, and W.R. Ott

SP 250-4 NBS Measurement Services:

Fricke Dosimetry in High-Energy

El ectron Beams

C.G. Soares, E.L. Bright and M. Ehrlich

SP 250-5 NBS Measurement Services:

Alpha-Particle Calibrations

J.M.R. Hutchinson

SP 250-6 NBS Measurement Services:

Regular Spectral Transmittance

K.L. Eckerle, J.J. Hsia, K.D. Mielenz, and V.R. Weidner

SP 250-7 NBS Measurement Services:

Radiance Temperature Calibrations

W.R. Waters, J.H. Walker, and A.T. Hattenburg

SP 250-8 NBS Measurement Services:

Spectral Reflect ance

V.R. Weidner and J.J. Hsia

SP 250-9 NBS Measurement Services:

Calibration of Beta-Particle-Emitting

Ophthalmic Applicators

J.S. Pruitt

SP 250-10 NBS Measurement Services:

Radioactivity Calibrations with the " $4 \pi$ "

Gamma Ionization Chamber, and Other

Radioact ivity Calibration Capabilities

J.M. Calhoun

SP 250-11 NBS Measurement Services:

Dosimetry for High-Dose Applications

J.C. Humphreys, D. Hocken, and W.L. MCLaughlin
SP 250-12 NBS Measurement Services: Neutron Personnel Dosimetry R.B. Schwartz

SP 250-13 NBS Measurement Services: Act ivation Foil Irradiation with Californium Fission Sources G.P. Lamaze and J.A. Grundl

SP 250-14 NBS Measurement Services:

Act ivation Foil Irradiation by Reactor Cavity Fission Sources

G.P. Lamaze and J.A. Grund 1

SP 250-15 NBS Measurement Services:

Photometric Calibrations

R.L. Booker and D.A. McSparron

SP 250-16 NBS Measurement Services:

Calibration of $X-R a y$ and Gamma-Ray

Measuring Instruments

P.J. Lamperti, T.P. Loftus, and R. Loevinger

SP 250-17 NBS Measurement Services:

The NBS Photodetector Spectral Response

Calibration Transfer Program

E.F. Zalewski

SP 250-18 NBS Measurement Services:

Neutron Source Strength Calibrations

E.D. McGarry and E.W. Boswell

SP 250-19 NBS Measurement Services:

Calibration of Gamma-Ray-Emitting

Brachytherapy Sources

J.T. Weaver, T.P. Loftus, and R. Loevinger

SP 250-20 NBS Measurement Services:

Spectral Irradiance Calibrations

J.H. Walker, R.D. Saunders, J.K. Jackson, and D.A. McSparron

SP 250-21 NBS Measurement Services:

Calibration of Beta-Particle

Radiation Instrumentation and Sources

J.S. Pruitt, C.G. Soares, and M. Ehrlich 
U.S. Department of Commerce

National Bureau of Standards

Gaithersburg, MD 20899

Official Business

Penalty for Private Use $\$ 300$ 